\title{
RESEARCH
}

Open Access

\section{Four subgroups based on tau levels in Alzheimer's disease observed in two independent cohorts}

Flora H. Duits ${ }^{1 \dagger}$, Kirsten E. J. Wesenhagen ${ }^{1 * \dagger}$ (D), Laura Ekblad ${ }^{1,2}$, Emma Wolters ${ }^{1,3}$, Eline A. J. Willemse ${ }^{4}$, ADNI, $^{2}$ Philip Scheltens ${ }^{1}$, Wiesje M. van der Flier ${ }^{1,5}$, Charlotte E. Teunissen ${ }^{4}$, Pieter Jelle Visser ${ }^{1,6,7}$ and Betty M. Tijms ${ }^{1}$

\begin{abstract}
Background: As Alzheimer's disease (AD) pathology presents decades before dementia manifests, unbiased biomarker cut-points may more closely reflect presence of pathology than clinically defined cut-points. Currently, unbiased cerebrospinal fluid (CSF) tau cut-points are lacking.

Methods: We investigated CSF t-tau and p-tau cut-points across the clinical spectrum using Gaussian mixture modelling, in two independent cohorts (Amsterdam Dementia Cohort and ADNI).

Results: Individuals with normal cognition (NC) (total $n=1111$ ), mild cognitive impairment (MCI) (total $n=1213$ ) and Alzheimer's disease dementia (AD) (total $n=1524$ ) were included. In both cohorts, four CSF t- and p-tau distributions and three corresponding cut-points were identified. Increasingly high tau subgroups were characterized by steeper MMSE decline and higher progression risk to AD (cohort/platform-dependent HR, t-tau 1.9-21.3; p-tau 2.2-9.5).
\end{abstract}

Limitations: The number of subjects in some subgroups and subanalyses was small, especially in the highest tau subgroup and in tau PET analyses.

Conclusions: In two independent cohorts, t-tau and p-tau levels showed four subgroups. Increasingly high tau subgroups were associated with faster clinical decline, suggesting our approach may aid in more precise prognoses.

Keywords: Alzheimer's disease, CSF tau, Gaussian mixture modelling, Prognosis

\footnotetext{
* Correspondence: k.wesenhagen@amsterdamumc.nl

Part of the data used in preparation of this article were obtained from the Alzheimer's Disease Neuroimaging Initiative (ADNI) database (adni.loni.usc.edu). As such, the investigators within the ADNI contributed to the design and implementation of ADNI and/or provided data but did not participate in analysis or writing of this report. A complete listing of ADNI investigators can be found at: https://adni.loni.usc.edu/wpcontent/uploads/ how_to_apply/ADNI_Acknowledgement_List.pdf.

${ }^{\dagger}$ Flora H. Duits and Kirsten E. J. Wesenhagen contributed equally to this work.

'Department of Neurology, Alzheimer Center Amsterdam, Amsterdam

Neuroscience, Vrije Universiteit Amsterdam, Amsterdam UMC, Amsterdam,

the Netherlands

Full list of author information is available at the end of the article
}

(C) The Author(s). 2020 Open Access This article is licensed under a Creative Commons Attribution 4.0 International License, which permits use, sharing, adaptation, distribution and reproduction in any medium or format, as long as you give appropriate credit to the original author(s) and the source, provide a link to the Creative Commons licence, and indicate if changes were made. The images or other third party material in this article are included in the article's Creative Commons licence, unless indicated otherwise in a credit line to the material. If material is not included in the article's Creative Commons licence and your intended use is not permitted by statutory regulation or exceeds the permitted use, you will need to obtain permission directly from the copyright holder. To view a copy of this licence, visit http://creativecommons.org/licenses/by/4.0/. The Creative Commons Public Domain Dedication waiver (http://creativecommons.org/publicdomain/zero/1.0/) applies to the data made available in this article, unless otherwise stated in a credit line to the data. 


\section{Background}

Abnormal levels of amyloid- $\beta$ 1-42 (A $\beta 42)$, total tau ( $t$ tau) and tau phosphorylated at threonine 181 (p-tau-181) are biomarkers for the presence of Alzheimer's disease (AD) pathology in the brain [1], and part of established research criteria for AD across the cognitive continuum [2, 3]. Classification schemes based on biomarkers depend on cut-points, and different approaches exist to determine such cut-points. The most often used traditional approach determines cut-points by optimizing the sensitivity and specificity to detect clinical AD-type dementia compared to controls [4-6]. However, approaches that use clinical labels as outcomes may not be optimal, because clinical labels do not optimally reflect the absence or presence of AD pathology: For example, almost $30 \%$ of cognitively intact individuals in their seventies have AD pathology [7], and up to $20 \%$ of clinical AD dementia cases do not show $\mathrm{AD}$ pathology at neuropathological examination [8-11]. As such, cut-point based on clinical labels can be biased.

Gaussian mixture modelling provides an approach to determine cut-points independent of clinical information [12]. This approach is based on the notion that the distribution of biomarker values in a population is a mixture of values belonging to subpopulations, i.e. normal and affected individuals. Previous studies using this approach have found a bimodal distribution of $A \beta 42$ levels, of which the cut-point (i.e. the intersection of these distributions) was higher than clinically based cutpoints, resulting in more sensitive detection of predementia AD [13-16]. As of yet, however, it remains unclear whether it is also possible to detect unbiased cutpoints in $\mathrm{t}$-tau and $\mathrm{p}$-tau levels.

High t-tau levels in the cerebrospinal fluid (CSF) are thought to reflect neuronal degeneration or injury, and elevated $t$-tau levels can be found in the CSF in various conditions involving neuronal death, for example after an acute stroke. In contrast, p-tau-181 is presumed to reflect the formation of phosphorylated tau in the brain and to represent more specifically the formation of neurofibrillary tangles, one of the neuropathological hallmarks of $\mathrm{AD}[17,18]$. As tau pathology is a hallmark of $\mathrm{AD}$, it can be hypothesized that similarly to amyloid, $\mathrm{t}$ and $\mathrm{p}$-tau levels may be a mixture of values belonging to normal and affected individuals, from which unbiased cut-points might be determined.

The objective of this study was to investigate whether subgroups can be identified in CSF t- and p-tau levels using Gaussian mixture modelling and to determine cutpoints. We characterized tau subgroups in terms of clinical and biological characteristics and longitudinal trajectories of cognitive decline. We repeated analyses in the independent ADNI cohort to determine the robustness of the identified subgroups and tested stability of group membership by studying longitudinal changes in $t$-tau

Table 1 Participant characteristics of the Amsterdam Dementia Cohort (ADC) and ADNI cohorts

\begin{tabular}{|c|c|c|c|c|c|c|}
\hline \multirow[b]{2}{*}{ Characteristic } & \multicolumn{3}{|l|}{ ADC } & \multicolumn{3}{|l|}{ ADNI } \\
\hline & $\begin{array}{l}N C \\
N=740\end{array}$ & $\begin{array}{l}\mathrm{MCl} \\
N=591\end{array}$ & $\begin{array}{l}\text { AD dementia } \\
N=1296\end{array}$ & $\begin{array}{l}N C \\
N=371\end{array}$ & $\begin{array}{l}\mathrm{MCl} \\
N=622\end{array}$ & $\begin{array}{l}\text { AD dementia } \\
N=228\end{array}$ \\
\hline MMSE, mean $\pm S D$ & $28.2 \pm 1.8$ & $26.5 \pm 2.4^{a}$ & $20.5 \pm 5^{c}$ & $29.1 \pm 1.2$ & $27.7 \pm 1.8^{a}$ & $23.3 \pm 2^{c}$ \\
\hline Age, mean $\pm S D$ & $59.6 \pm 8.9$ & $66.4 \pm 8.2^{a}$ & $66.2 \pm 8.1^{a}$ & $73.8 \pm 5.9$ & $72.4 \pm 7.5^{a}$ & $74.9 \pm 8.1^{b}$ \\
\hline Female, $n(\%)$ & $306(41.4 \%)$ & $217(36.7 \%)^{a}$ & $674(52 \%)^{c}$ & $195(52.6 \%)$ & $255(41 \%)^{a}$ & $95(41.7 \%)^{c}$ \\
\hline APOE e4 carrier, $n(\%)$ NC & $258(36.3 \%)$ & $287(52.4 \%)^{a}$ & $791(65.3 \%)^{c}$ & $103(27.8 \%)$ & $307(49.4 \%)^{a}$ & $154(67.5 \%)^{c}$ \\
\hline Innotest: T-tau (pg/ml), mean \pm SD & $296.4 \pm 200.8$ & $466.4 \pm 303.6^{a}$ & $716.6 \pm 417.1^{c}$ & n.a. & n.a. & n.a. \\
\hline Innotest: P-tau (pg/ml), mean \pm SD & $48.4 \pm 22.7$ & $66.8 \pm 33.6^{a}$ & $87.6 \pm 39.5^{c}$ & n.a. & n.a. & n.a. \\
\hline Innotest: $A \beta 42(p g / m l)$, mean $\pm S D$ & $1071.2 \pm 246.9$ & $859.1 \pm 288.1^{a}$ & $648.4 \pm 166.6^{c}$ & n.a. & n.a. & n.a. \\
\hline Innotest: Abnormal Aß42 (<813 pg/ml), n (\%) & $124(16.8 \%)$ & $326(55.2 \%)^{a}$ & $1173(90.5 \%)^{c}$ & n.a. & n.a. & n.a. \\
\hline Luminex T-tau $(\mathrm{pg} / \mathrm{ml})$, mean $\pm \mathrm{SD}$ & n.a. & n.a. & n.a. & $67.4 \pm 32.8$ & $90.4 \pm 54.8^{a}$ & $126.6 \pm 61.4^{c}$ \\
\hline Luminex P-tau $(p g / m l)$, mean \pm SD & n.a. & n.a. & n.a. & $32.4 \pm 18.8$ & $39.2 \pm 23.7^{a}$ & $51.6 \pm 30.7^{c}$ \\
\hline Luminex $A \beta 42(p g / m l)$, mean $\pm S D$ & n.a. & n.a. & n.a. & $201.7 \pm 51.9$ & $171.2 \pm 52.5^{a}$ & $139.6 \pm 38.8^{c}$ \\
\hline Luminex Abnormal Aß42 (<192 pg/ml), n(\%) & n.a. & n.a. & n.a. & $156(42 \%)$ & $403(64.8 \%)^{a}$ & $210(92.1 \%)^{c}$ \\
\hline Elecsys T-tau (pg/ml), mean \pm SD & n.a. & n.a. & n.a. & $238.5 \pm 90$ & $284.9 \pm 126.7^{a}$ & $370.2 \pm 144.4^{c}$ \\
\hline Elecsys P-tau $(\mathrm{pg} / \mathrm{ml})$, mean $\pm \mathrm{SD}$ & n.a. & n.a. & n.a. & $21.9 \pm 9.2$ & $27.6 \pm 14.4^{a}$ & $36.9 \pm 15.7^{c}$ \\
\hline Elecsys $A \beta 42(\mathrm{pg} / \mathrm{ml})$, mean $\pm \mathrm{SD}$ & n.a. & n.a. & n.a. & $1337 \pm 647.9$ & $1020.7 \pm 554.8^{a}$ & $694.6 \pm 420.7^{c}$ \\
\hline Elecsys Abnormal A $442(<880$ pg/ml), $n(\%)$ & n.a. & n.a. & n.a. & $104(28 \%)$ & $325(53 \%)^{a}$ & $189(85 \%)^{c}$ \\
\hline
\end{tabular}

n.a. not available, $N C$ cognitively normal, $M C l$ mild cognitive impairment, $A D$ Alzheimer's disease

${ }^{\mathrm{a} D i f f e r s}$ from NC with $p<.05$

${ }^{\mathrm{b}}$ Differs from $\mathrm{MCl}$ with $p<.001$

${ }^{c}$ Differs from $\mathrm{MCl}$ and $\mathrm{NC}$ with $p<.001$ 
and p-tau levels. Finally, we compared subgroups on tau PET uptake that was available for a subset of individuals in ADNI.

\section{Methods}

We investigated the existence of CSF $t$ - and p-tau subgroups in data from two independent clinical cohorts. The memory clinic-based Amsterdam Dementia Cohort (ADC) was used for testing our hypothesis [19], and the Alzheimer's Disease Neuroimaging Initiative (ADNI; www.adni-info.org) was used for validation of the results. ADNI started in 2003 as a public-private collaboration under the supervision of Principal Investigator Michael W. Weiner, MD. The primary goal of ADNI is to study whether serial magnetic resonance imaging (MRI), positron emission tomography (PET), other biological markers and clinical and neuropsychological measures can be combined to measure the progression of mild cognitive impairment (MCI) and early Alzheimer's disease (AD). Please see www.adni-info.org for the latest information.
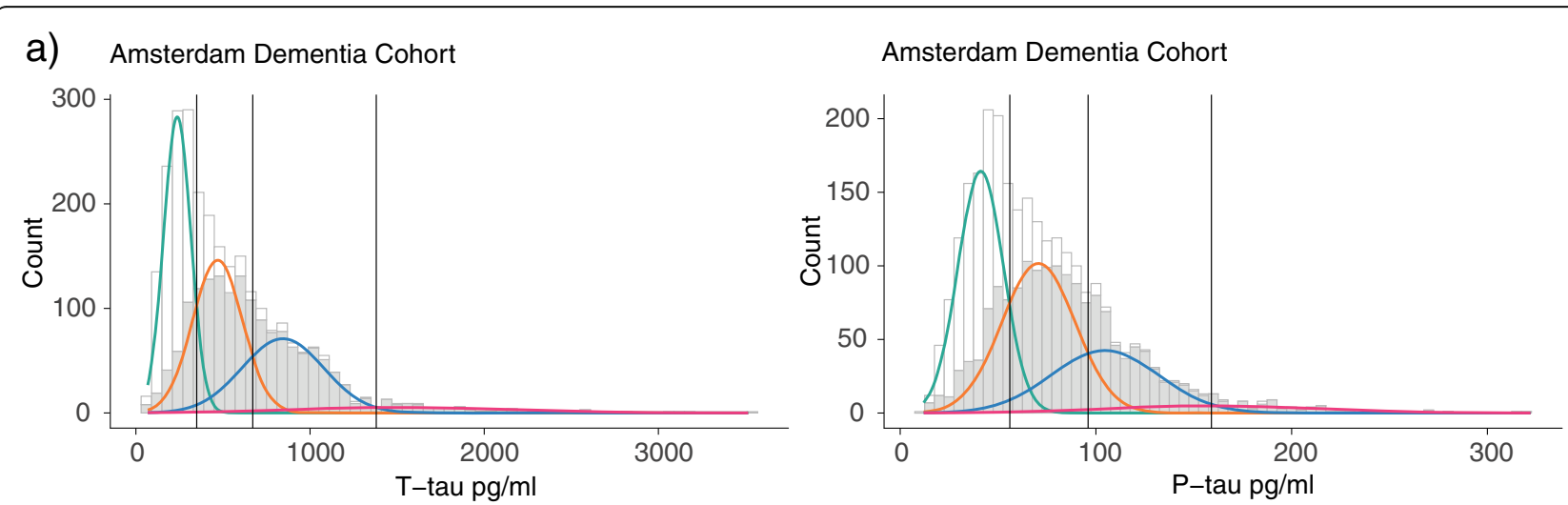

b) ADNI Luminex
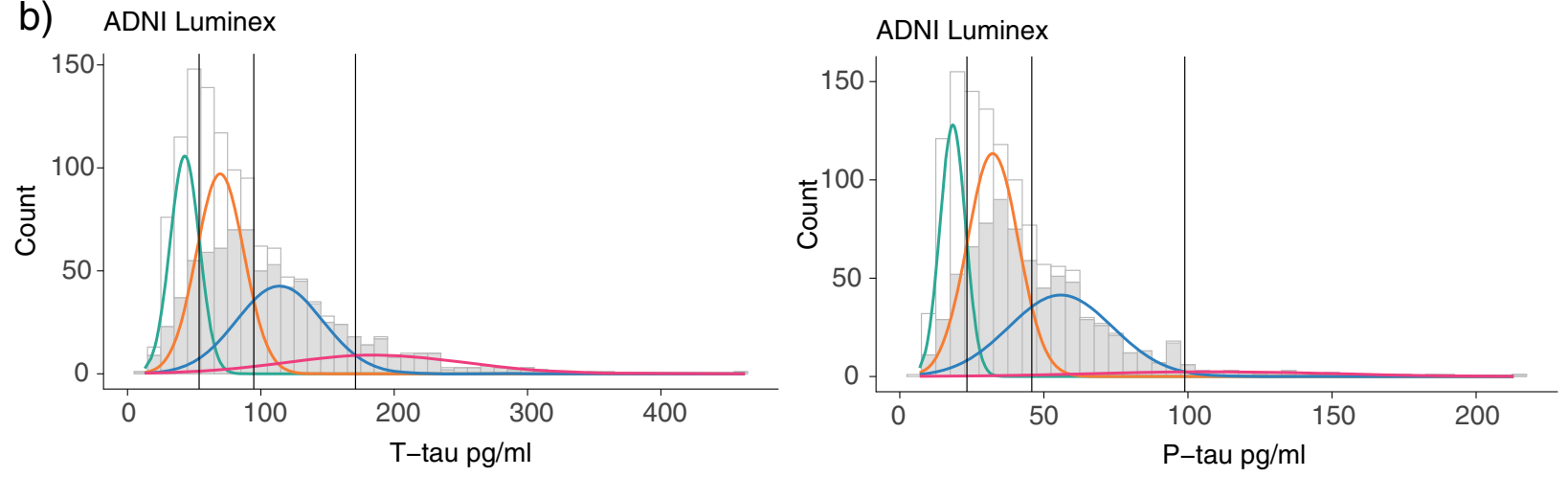

c) ADNI Elecsys
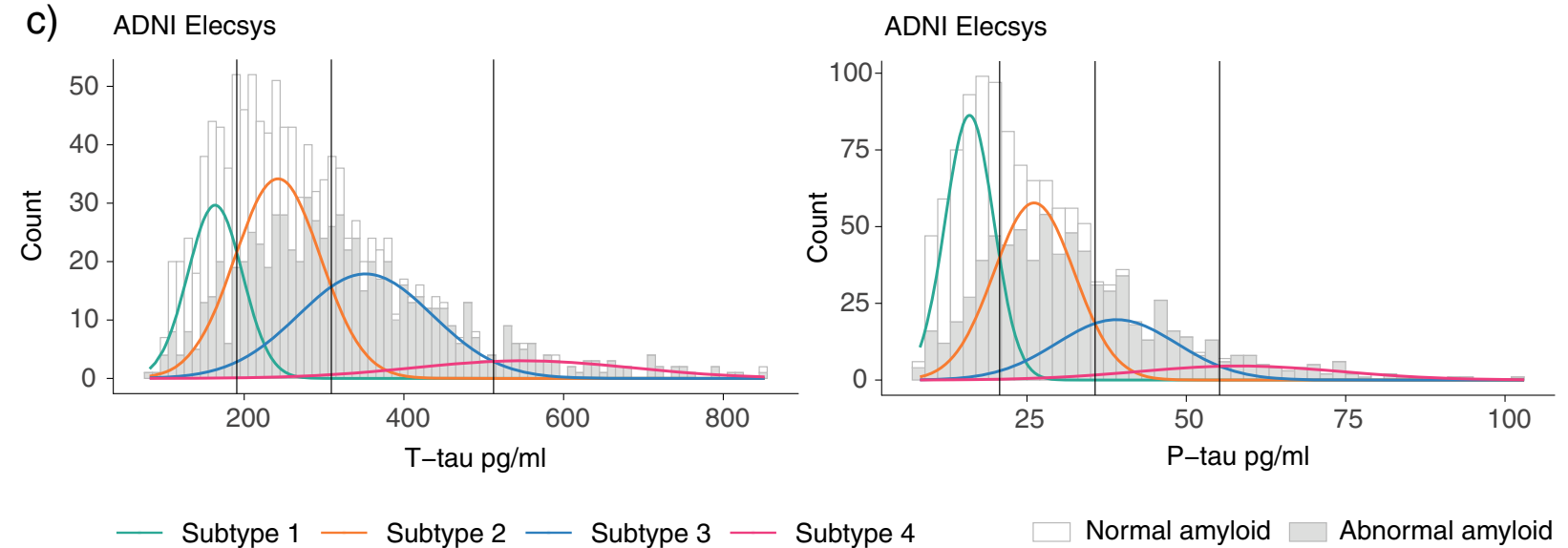

Fig. 1 Tetramodal distributions in t-tau and p-tau levels in ADC and ADNI. Levels in ADC are shown in (a); levels in ADNI are shown in (b) for Luminex and (c) for Elecsys assay. Grey colours in the distributions reflect for those tau levels the number of individuals with abnormal amyloid levels 
The institutional review boards of all participating institutions approved the procedures for this study. Written informed consent was obtained from all participants or surrogates. Participant selection and CSF analyses are summarized below; for more detailed methods and information on Apolipoprotein E (APOE) genotyping and PET imaging, see Additional file 1.

\section{Participants}

In short, patients from the ADC who visited our memory clinic between November 2000 and December 2016 were selected $(n=2724)$ if they had baseline CSF tau measurements available and had subjective cognitive decline (considered as normal cognition (NC)), mild cognitive impairment $(\mathrm{MCI})$ or $\mathrm{AD}$ dementia. Participants from ADNI who had baseline CSF biomarkers available were selected $(n=1221)$ for the replication analyses if they met the study-specific criteria of $\mathrm{NC}, \mathrm{MCI}$ or dementia. A subset of 619 individuals in ADNI (51\%; 183 $\mathrm{NC}, 345 \mathrm{MCI}$ and 91 with $\mathrm{AD}$ dementia) with available follow-up CSF measures were selected for longitudinal analyses.

\section{CSF biomarkers}

In ADC, CSF biomarkers ( $\beta$-amyloid $(1-42)$, hTAU-Ag, and phospo-tau 181P) were assessed with INNOTEST (Fujirebio, Ghent, Belgium) on a routine basis as described before [20]. In ADNI, CSF biomarkers were analysed using a multiplex xMAP Luminex platform (Luminex Corp) with immunoassay kit-based reagents (INNO-BIA Alzbio3; Innogenetics) [21] ( $n=1213$ participants), and on Elecsys (Roche, Basel, Switserland) [21] ( $n=1193$ participants, overlap with Luminex 98\%).

\section{Statistical analysis}

Gaussian mixture modelling was used to identify cutpoints in the distribution of $\mathrm{t}$-tau and $\mathrm{p}$-tau values. First, the number of distributions that best described the data was determined with the $\mathrm{R}$ boot.comp function. This function sequentially tests increasing number of components in the data using parametric bootstrapping of the likelihood ratio (i.e. likelihood of $\mathrm{x}$ components vs. likelihood of having one more component, i.e. $x+1$ ), until the null hypothesis cannot be rejected anymore $(p>$ 0.05 , i.e. no improvement of additional component for model fit). Then, we identified data-driven cut-points as the points where the lines of two fitted Gaussian distributions intersected. Using these cut-points, we labelled subjects according to tau subgroups. Next, within each cohort, we compared subgroups based on demographical, clinical and biological characteristics with ANOVA or chi-square tests, when appropriate. For a subset of individuals with available repeated mini-mental state examination (MMSE) and/or clinical follow-up, we further assessed whether subgroups showed differences in cognitive decline, stratifying subjects based on their baseline cognitive state (defined as NC, MCI or dementia). First, decline in MMSE (outcome) was assessed with linear mixed models using the R package "lmer4", including the main terms time and tau subgroup, and interaction terms time"tau subgroup. For individuals without dementia at baseline, Cox proportional hazards models were used to compare the rate of progression from $\mathrm{NC}$ to $\mathrm{MCI}$ or $\mathrm{AD}$ dementia and from MCI to AD dementia between tau subgroups. We ran 5 models: (1) without covariates; (2) including age, sex and educational level; (3) model 2 + amyloid status; (4) model 3 + baseline cognitive state; and (5) model $4+$ APOE-e 4 carriership (dichotomous). For the Cox proportional hazards models, data from

Table 2 Consistency of subgroup labelling between t-tau and p-tau (ADC and ADNI), and across platforms (ADNI)

\begin{tabular}{|c|c|c|c|c|c|}
\hline \multirow{2}{*}{$\begin{array}{l}\text { Biomarker: Platform } \\
\text { ADC T-tau: Innotest }\end{array}$} & \multicolumn{5}{|c|}{ ADC p-tau Innotest } \\
\hline & Subgroup & 1 & 2 & 3 & 4 \\
\hline & 1 & 960 & 83 & 0 & 0 \\
\hline & 2 & 140 & 661 & 58 & 0 \\
\hline & 3 & 6 & 209 & 399 & 18 \\
\hline & 4 & 0 & 0 & 33 & 60 \\
\hline & & P-tau & & & \\
\hline \multirow[t]{6}{*}{ T-tau: Luminex } & Subgroup & 1 & 2 & 3 & 4 \\
\hline & 1 & 210 & 108 & 13 & 1 \\
\hline & 2 & 116 & 261 & 89 & 2 \\
\hline & 3 & 3 & 159 & 138 & 8 \\
\hline & 4 & 0 & 10 & 76 & 19 \\
\hline & & P-tau & & & \\
\hline \multirow[t]{6}{*}{ T-tau: Elecsys } & Subgroup & 1 & 2 & 3 & 4 \\
\hline & 1 & 290 & 0 & 0 & 0 \\
\hline & 2 & 186 & 309 & 0 & 0 \\
\hline & 3 & 0 & 145 & 185 & 2 \\
\hline & 4 & 0 & 0 & 14 & 61 \\
\hline & & T-tau & & & \\
\hline \multirow[t]{6}{*}{ T-tau: Luminex } & Subgroup & 1 & 2 & 3 & 4 \\
\hline & 1 & 256 & 70 & 1 & 0 \\
\hline & 2 & 35 & 381 & 43 & 1 \\
\hline & 3 & 0 & 44 & 255 & 4 \\
\hline & 4 & 0 & 0 & 33 & 70 \\
\hline & & P-tau & & & \\
\hline \multirow[t]{5}{*}{ P-tau: Luminex } & Subgroup & 1 & 2 & 3 & 4 \\
\hline & 1 & 287 & 36 & 0 & 0 \\
\hline & 2 & 167 & 296 & 63 & 2 \\
\hline & 3 & 21 & 119 & 121 & 48 \\
\hline & 4 & 0 & 1 & 13 & 12 \\
\hline
\end{tabular}




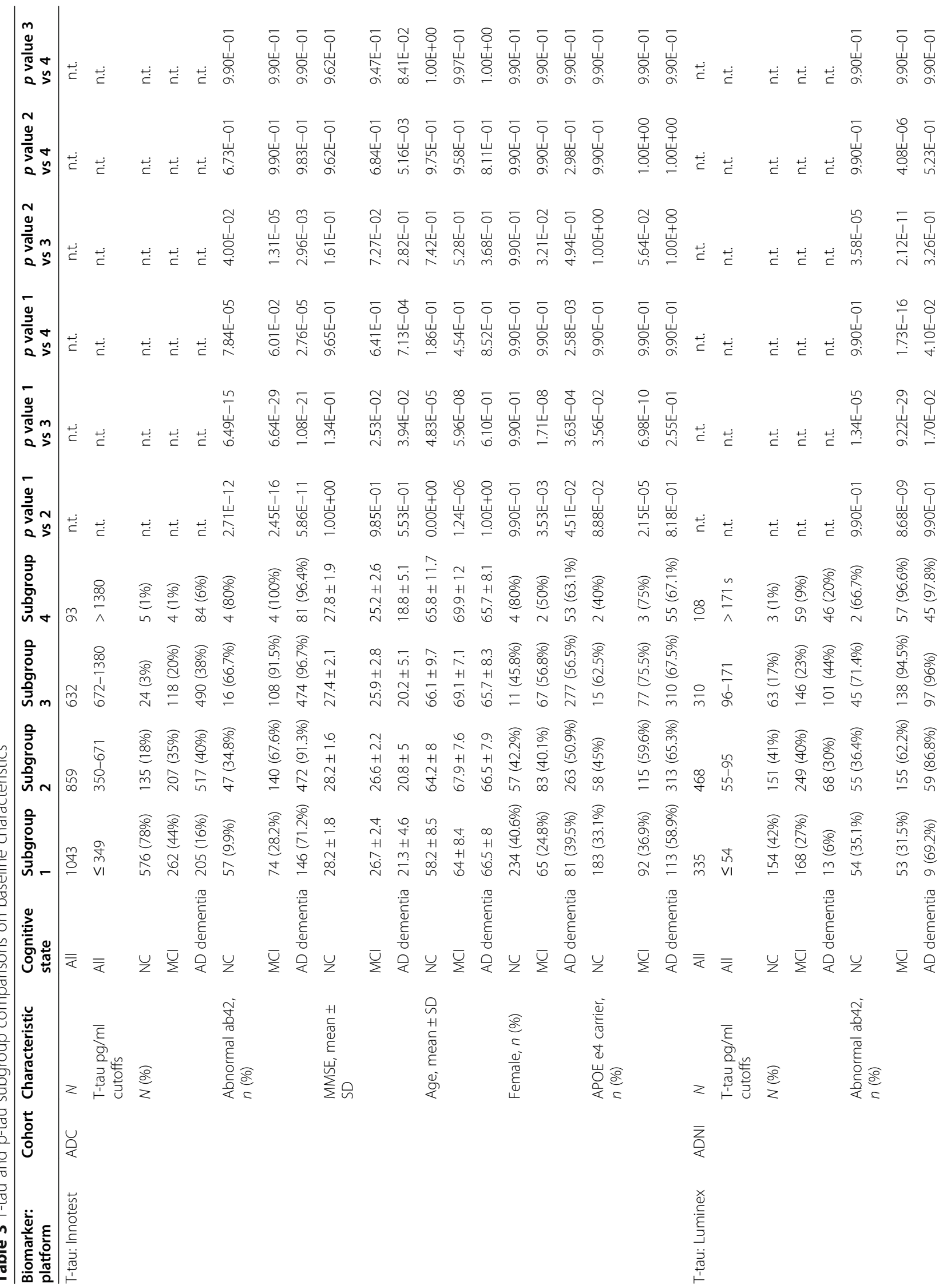




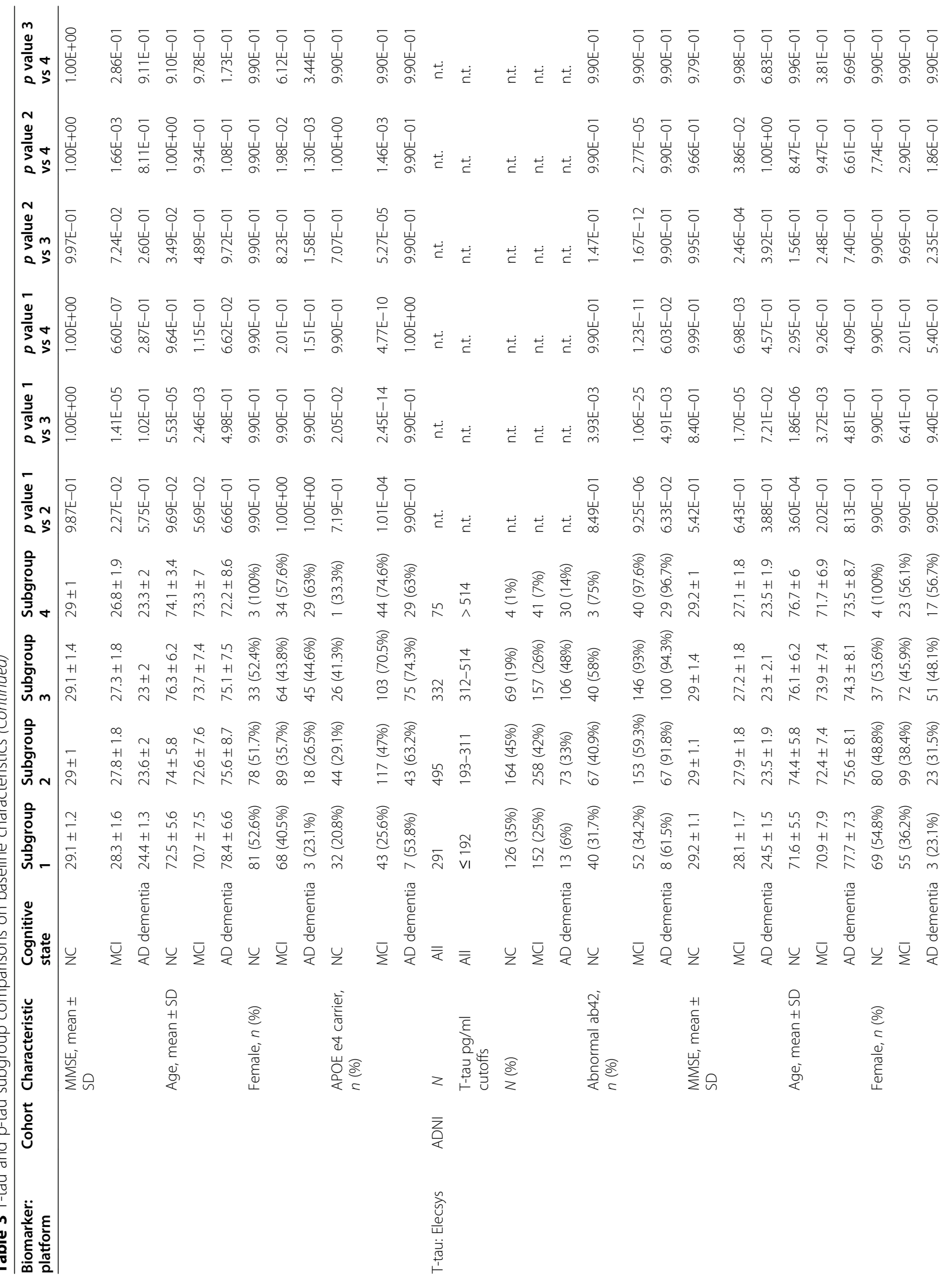




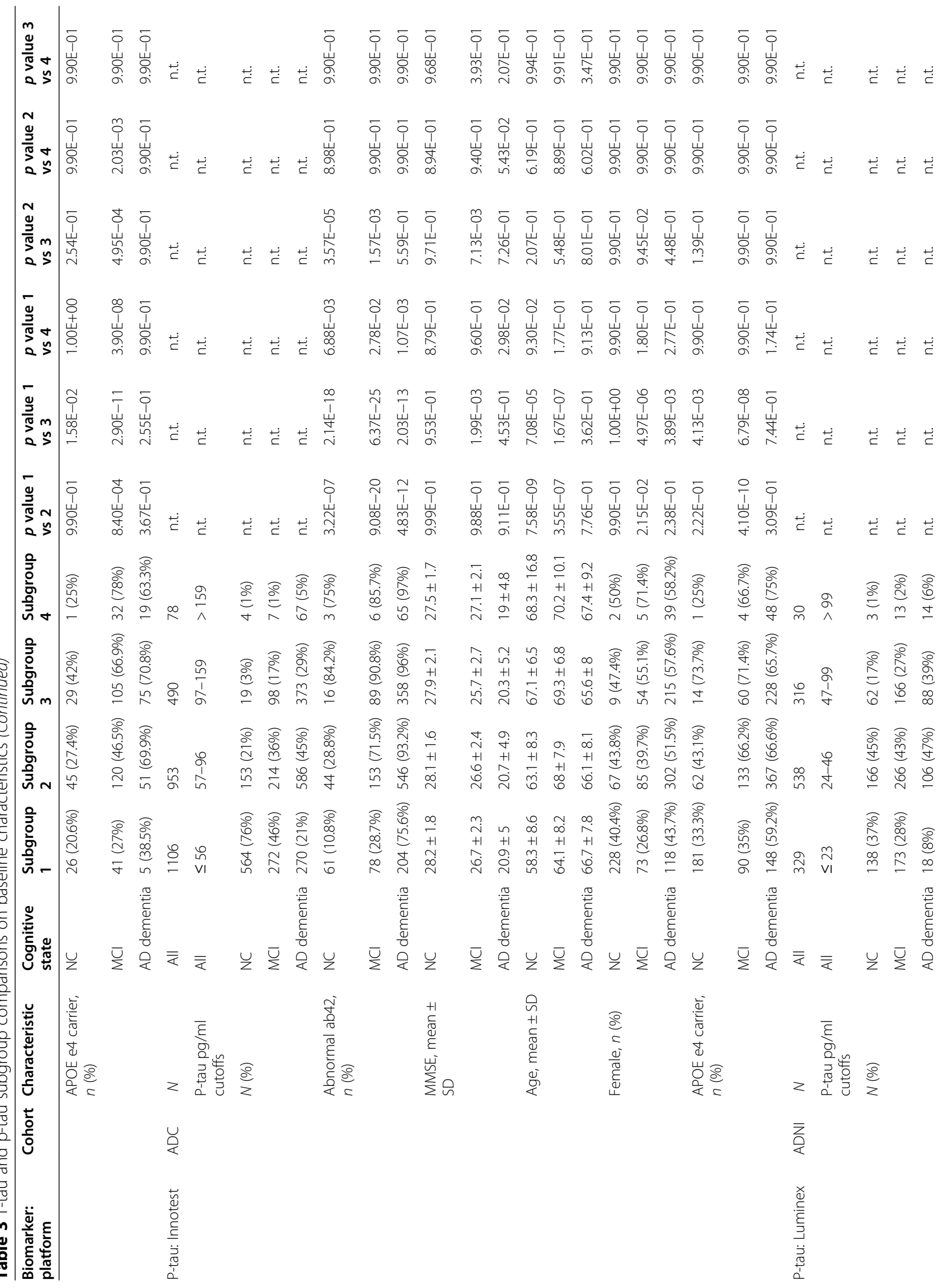




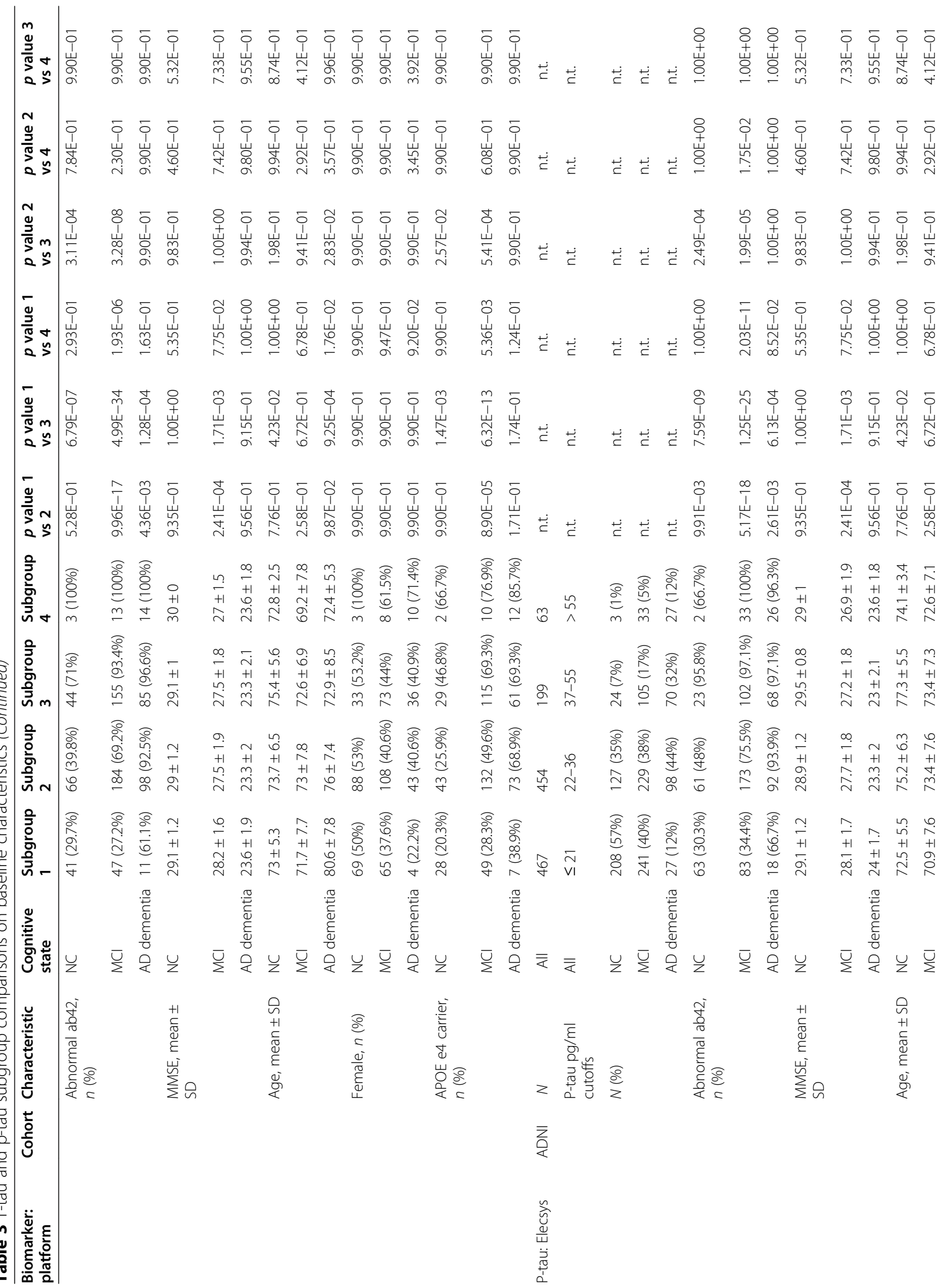




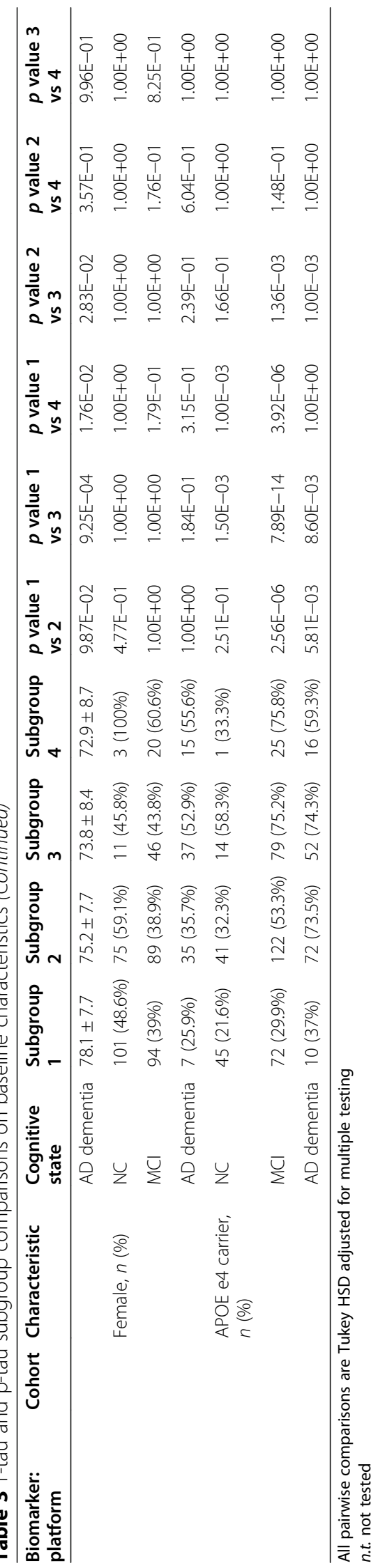


945 subjects was available ( 357 normal and $588 \mathrm{MCI}$ subjects). Subsets of individuals in ADNI also had repeated CSF tau measures available, for which we tested changes over time in tau subgroups, or had TAU PET available, for which we compared tau uptake according to Braak stages between subgroups. All analyses except for Cox proportional hazard analyses were stratified for baseline cognitive state, and adjusted for age and sex, and cognitive outcomes additionally for level of education [22]. In Cox proportional hazard analyses, no stratification for baseline cognitive state was performed due to small size of the resulting groups; instead, baseline cognitive state was added as additional covariate. All statistical analyses were performed in R version 3.6.1 "Action of the Toes", mixture modelling was performed with the mixtools package (version 1.1.0), estimated marginal means and trends were computed with the R package "emmeans" v1.4, and sensitivity and specificity analyses with epiR v.1.0-15.

\section{Results}

\section{Patient characteristics}

Table 1 shows baseline characteristics of the ADC and ADNI cohorts. Compared to the ADC, subjects in the ADNI cohort were approximately 10 years older and had a lower prevalence of $\mathrm{AD}$ dementia and a higher prevalence of MCI. In ADC, subjects with $\mathrm{NC}$ were about 7 years younger compared to $\mathrm{MCI}$ and $\mathrm{AD}$ patients, and the $\mathrm{NC}$ and the $\mathrm{MCI}$ subjects were more often male than AD dementia subjects. In ADNI, MCI subjects were youngest, and $\mathrm{MCI}$ and $\mathrm{AD}$ dementia subjects were more often male than NC. In both cohorts, AD dementia subjects had lowest baseline MMSE scores, highest proportion of APOE e4 carriers, lowest levels of $\mathrm{A} \beta 42$, and highest levels of tau. MCI subjects had values in between $\mathrm{NC}$ subjects and $\mathrm{AD}$ dementia patients.

\section{Gaussian mixture modelling reveals four subgroups}

Mixture modeling showed that four distributions (i.e. a tetramodel distribution) best fitted the data for both $\mathrm{t}$ tau and p-tau levels, with an optimal fit for four distributions (log-likelihood ratio for 3 vs. 4 distributions, for $\mathrm{t}$ tau: 97.2, and p-tau: 28.3 , both $p<0.001$, no further improvement for 5 distributions: log-likelihood ratio for 5 vs 4 distributions, for $\mathrm{t}$-tau: 3.9 , and $\mathrm{p}$-tau 15 , both $p>$ 0.05 ; see Additional file 2 for fit statistics of all fitted models, and Fig. 1a for a visualisation of the four distributions). In the ADC (using Innotest), this yielded three cutoffs (95\% confidence interval (CI)), for $\mathrm{t}$-tau-349 (304-382), 671 (582-834) and $1380(1260-1505) \mathrm{pg} / \mathrm{mL}$, and for p-tau-56 (46-60), 96 (71-121) and 159 (138240) (for $n$ per subgroup defined by cut-points, see Tables 2 and 3). The first cut-points for t-tau $(349 \mathrm{pg} / \mathrm{mL})$ and $\mathrm{p}$-tau $(56 \mathrm{pg} / \mathrm{mL})$ were comparable to the $\mathrm{t}$-tau and p-tau cut-points of $375 \mathrm{pg} / \mathrm{ml}$ and $52 \mathrm{pg} / \mathrm{ml}$ we previously reported [5], and showed similar sensitivity and specificity performance to distinguish between clinical AD dementia and controls (see Table 4 for sensitivity and specificity comparisons). Sensitivity and specificity for distinguishing $\mathrm{NC}$ vs MCI were also comparable to those resulting from the clinical cut-point (Table 4).

T-tau and p-tau strongly correlated across the total group $(r=.92, p<.001)$; however, when comparing

Table 4 Sensitivity and specificity for clinical comparisons

\begin{tabular}{|c|c|c|c|c|c|c|c|c|c|c|}
\hline \multirow[b]{3}{*}{ Dataset } & \multirow[b]{3}{*}{$\begin{array}{l}\text { First cut- } \\
\text { point }\end{array}$} & \multirow[b]{3}{*}{$\begin{array}{l}\text { Cut-point } \\
\text { (literature) }\end{array}$} & \multicolumn{4}{|c|}{ NC vs AD-type dementia } & \multicolumn{4}{|l|}{$\mathrm{NC}$ vs $\mathrm{MCl}$} \\
\hline & & & \multicolumn{2}{|c|}{ First cut-point } & \multicolumn{2}{|c|}{ Cut-point (literature) } & \multicolumn{2}{|c|}{ First cut-point } & \multicolumn{2}{|c|}{ Cut-point (literature) } \\
\hline & & & Sensitivity & Specificity & Sensitivity & Specificity & Sensitivity & Specificity & Sensitivity & Specificity \\
\hline \multicolumn{11}{|l|}{ T-tau } \\
\hline $\begin{array}{l}\text { ADC: } \\
\text { Innotest }\end{array}$ & 349 & $375^{a}$ & $\begin{array}{l}0.84 \\
(0.8-0.86)\end{array}$ & $\begin{array}{l}0.78 \\
(0.74-0.82)\end{array}$ & $\begin{array}{l}0.81 \\
(0.78-0.84)\end{array}$ & $\begin{array}{l}0.82 \\
(0.78-0.86)\end{array}$ & $\begin{array}{l}0.56 \\
(0.52-0.6)\end{array}$ & $\begin{array}{l}0.78 \\
(0.75-0.81)\end{array}$ & $\begin{array}{l}0.52 \\
(0.47-0.56)\end{array}$ & $\begin{array}{l}0.82 \\
(0.79-0.84)\end{array}$ \\
\hline $\begin{array}{l}\text { ADNI: } \\
\text { Luminex }\end{array}$ & 54 & $93^{b}$ & $\begin{array}{l}0.95 \\
(0.9-0.98)\end{array}$ & $\begin{array}{l}0.4 \\
(0.33-0.48)\end{array}$ & $\begin{array}{l}0.64 \\
(0.55-0.72)\end{array}$ & $\begin{array}{l}0.81 \\
(0.74-0.86)\end{array}$ & $\begin{array}{l}0.73 \\
(0.69-0.76)\end{array}$ & $\begin{array}{l}0.42 \\
(0.36-0.47)\end{array}$ & $\begin{array}{l}0.35 \\
(0.31-0.39)\end{array}$ & $\begin{array}{l}0.81 \\
(0.76-0.84)\end{array}$ \\
\hline $\begin{array}{l}\text { ADNI: } \\
\text { Elecsys }\end{array}$ & 192 & $300^{c}$ & $\begin{array}{l}0.94 \\
(0.88-0.97)\end{array}$ & $\begin{array}{l}0.33 \\
(0.26-0.4)\end{array}$ & $\begin{array}{l}0.64 \\
(0.55-0.72)\end{array}$ & $\begin{array}{l}0.78 \\
(0.71-0.84)\end{array}$ & $\begin{array}{l}0.76 \\
(0.72-0.79)\end{array}$ & $\begin{array}{l}0.34 \\
(0.29-0.39)\end{array}$ & $\begin{array}{l}0.37 \\
(0.33-0.4)\end{array}$ & $\begin{array}{l}0.77 \\
(0.72-0.81)\end{array}$ \\
\hline \multicolumn{11}{|l|}{ P-tau } \\
\hline $\begin{array}{l}\text { ADC: } \\
\text { Innotest }\end{array}$ & 56 & $52^{\mathrm{a}}$ & $\begin{array}{l}0.78 \\
(0.75-0.81)\end{array}$ & $\begin{array}{l}0.77 \\
(0.72-0.81)\end{array}$ & $\begin{array}{l}0.83 \\
(0.8-0.86)\end{array}$ & $\begin{array}{l}0.72 \\
(0.68-0.77)\end{array}$ & $\begin{array}{l}0.54 \\
(0.5-0.58)\end{array}$ & $\begin{array}{l}0.76 \\
(0.73-0.79)\end{array}$ & $\begin{array}{l}0.59 \\
(0.55-0.63)\end{array}$ & $\begin{array}{l}0.7 \\
(0.67-0.73)\end{array}$ \\
\hline $\begin{array}{l}\text { ADNI: } \\
\text { Luminex }\end{array}$ & 23 & $23^{\mathrm{b}}$ & $\begin{array}{l}0.9 \\
(0.84-0.95)\end{array}$ & $\begin{array}{l}0.4 \\
(0.33-0.47)\end{array}$ & $\begin{array}{l}0.9 \\
(0.84-0.95)\end{array}$ & $\begin{array}{l}0.4 \\
(0.33-0.48)\end{array}$ & $\begin{array}{l}0.72 \\
(0.68-0.76)\end{array}$ & $\begin{array}{l}0.37 \\
(0.32-0.42)\end{array}$ & $\begin{array}{l}0.72 \\
(0.68-0.76)\end{array}$ & $\begin{array}{l}0.37 \\
(0.32-0.43)\end{array}$ \\
\hline $\begin{array}{l}\text { ADNI: } \\
\text { Elecsys }\end{array}$ & 21 & $24^{c}$ & $\begin{array}{l}0.84 \\
(0.76-0.9)\end{array}$ & $\begin{array}{l}0.56 \\
(0.48-0.63)\end{array}$ & $\begin{array}{l}0.8 \\
(0.72-0.87)\end{array}$ & $\begin{array}{l}0.67 \\
(0.6-0.74)\end{array}$ & $\begin{array}{l}0.61 \\
(0.57-0.65)\end{array}$ & $\begin{array}{l}0.56 \\
(0.51-0.61)\end{array}$ & $\begin{array}{l}0.5 \\
(0.46-0.54)\end{array}$ & $\begin{array}{l}0.68 \\
(0.63-0.72)\end{array}$ \\
\hline
\end{tabular}

$\mathrm{MCl}$ mild cognitive impairment, $\mathrm{NC}$ normal cognition

asource: [5]

bSource: [21]

'Source: [23] 

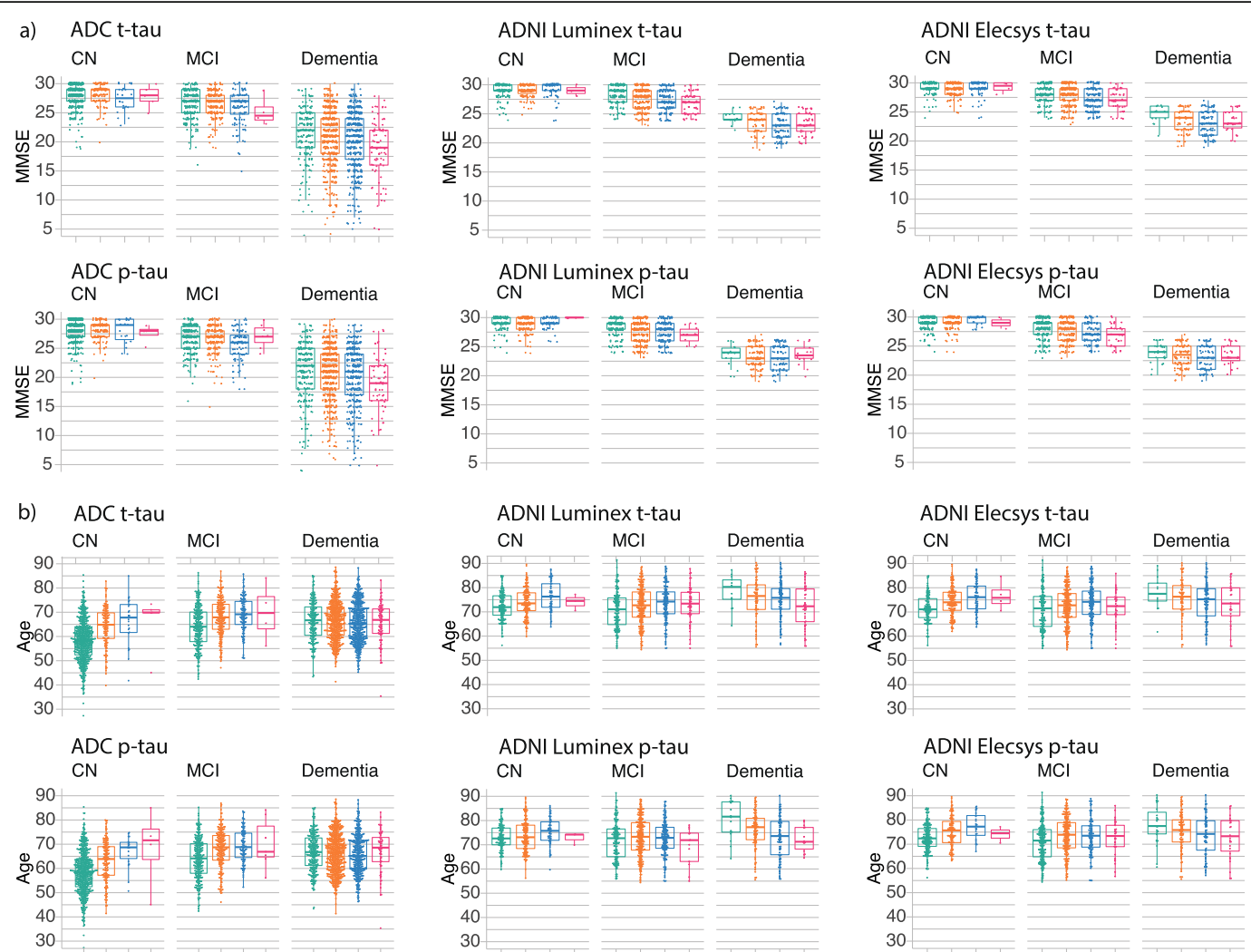

c) $\quad A D C t-t a u$
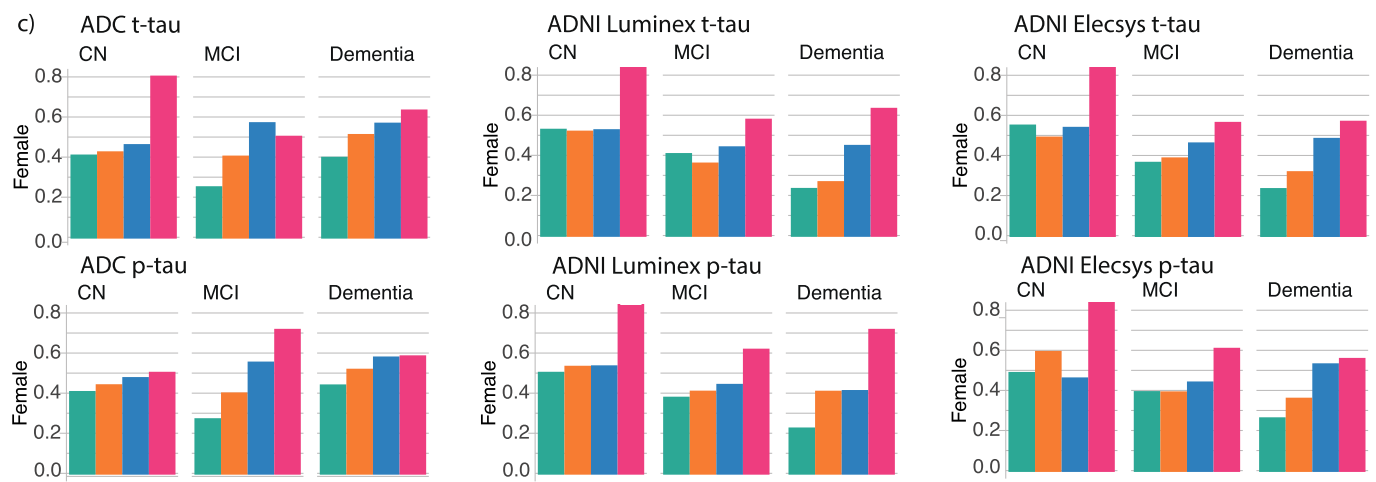

Dementia
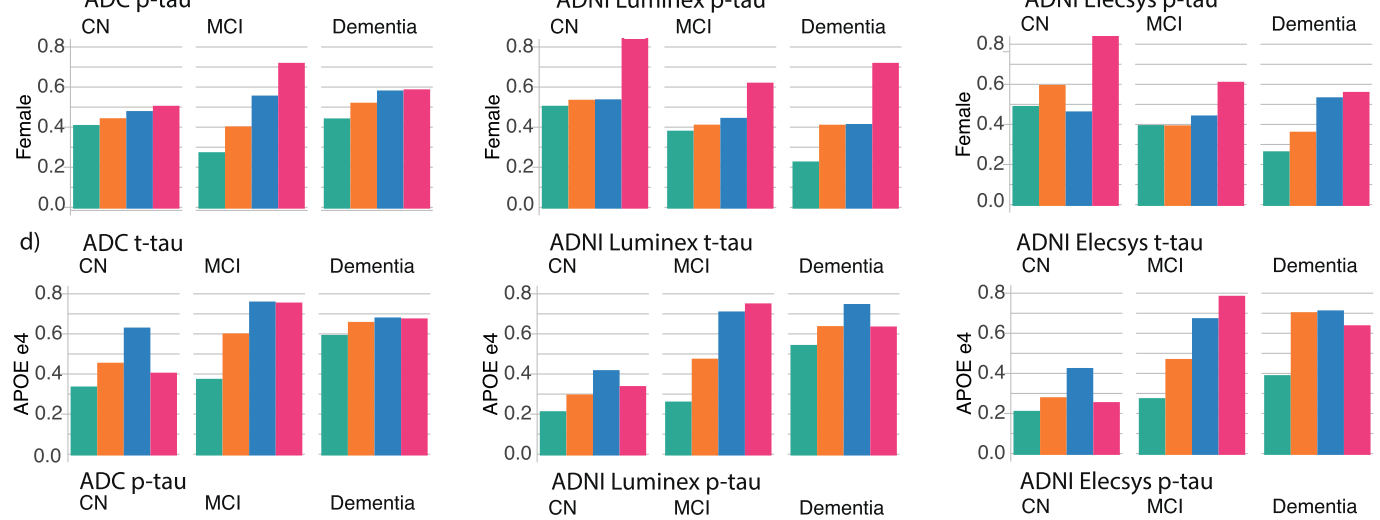

Dementia
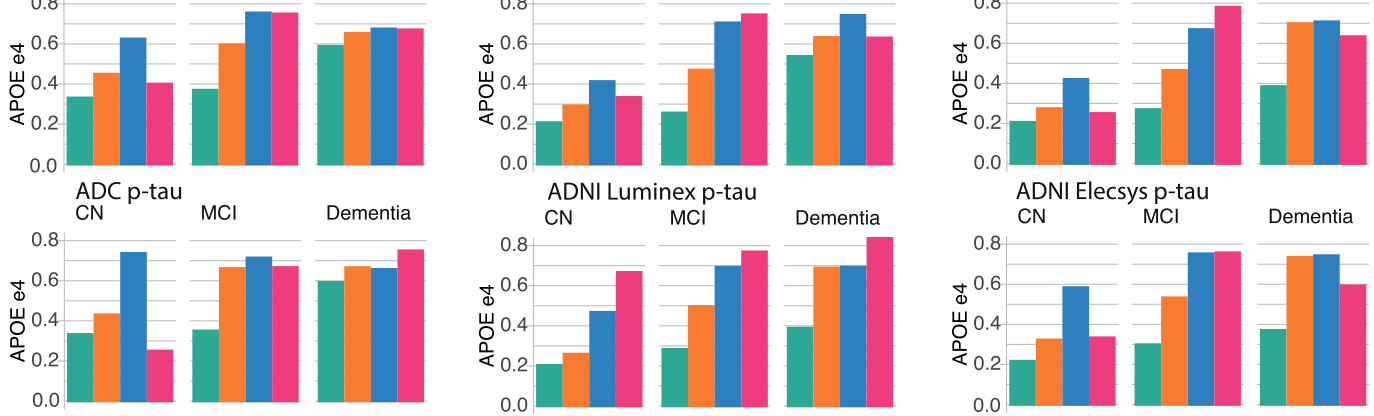

- Subtype 1

1 - Subtype 2

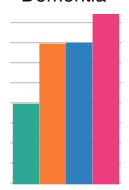

\section{- Subtype 4}

Fig. 2 T-tau and p-tau subgroup comparisons within each cohort, stratified for cognitive state. Left, ADC; middle, ADNI Luminex; right, ADNI Elecsys. Comparisons for MMSE are shown in (a), for age in (b), for proportion female in (c) and for proportion of APOE-e4 carriers in (d). See Table 3 for statistical descriptions. NC, normal cognition; MCl, mild cognitive impairment; AD dementia, AD-type dementia 
classification of individuals based on t-tau and p-tau, concordance was somewhat lower (79\%; Table 2). Applying mixture modelling in ADNI showed that similar to the ADC, a tetramodal distribution best fitted the CSF ttau and p-tau data (log-likelihood ratio for 3 vs 4 distributions, for t-tau: 25.2 and for p-tau: 54.3 , both with $p<$ 0.05 , no further improvement for 5 distributions: loglikelihood ratio for 5 vs 4 distributions, for t-tau: 11.2, and p-tau: 20.3, with $p=0.08$ and $p=0.05$, respectively). The tetramodal distribution yielded three different cutpoints for t-tau measured with Luminex (95\%CI) - 54 (42-68), 95 (68-125) and 171 (146-263) pg/mL respectively (Fig. 1b), and for p-tau levels (95\%CI)-23 (20-28), 46 (38-57) and 99 (74-124). Comparing the first cut- point of t-tau $(54 \mathrm{pg} / \mathrm{mL})$ with the cut-point of $93 \mathrm{pg} / \mathrm{mL}$ previously determined for ADNI [21], our new cut-point for $\mathrm{t}$-tau resulted in higher sensitivity to detect clinical $\mathrm{AD}$ dementia versus controls, at the cost of lower specificity (Table 4$)$. The first p-tau cut-point $(23 \mathrm{pg} / \mathrm{mL})$ was identical to the cut-point reported in the literature [21].

In ADNI, we further repeated analyses on the novel Elecsys data as an analytical validation, and again observed a tetramodal distribution for $\mathrm{t}$-tau (log-likelihood ratio for 3 vs 4 distributions, for $\mathrm{t}$-tau: 12.4 , and p-tau: 19.6, both with $p<0.05$, no further improvement for 5 distributions: $\log$-likelihood ratio for 5 vs 4 distributions, for t-tau: 7.1, and p-tau 10.6, both $p>0.05$ ). The tetramodal distribution yielded for $\mathrm{t}$-tau the cut-points $(95 \% \mathrm{CI})-192$ (129-235),

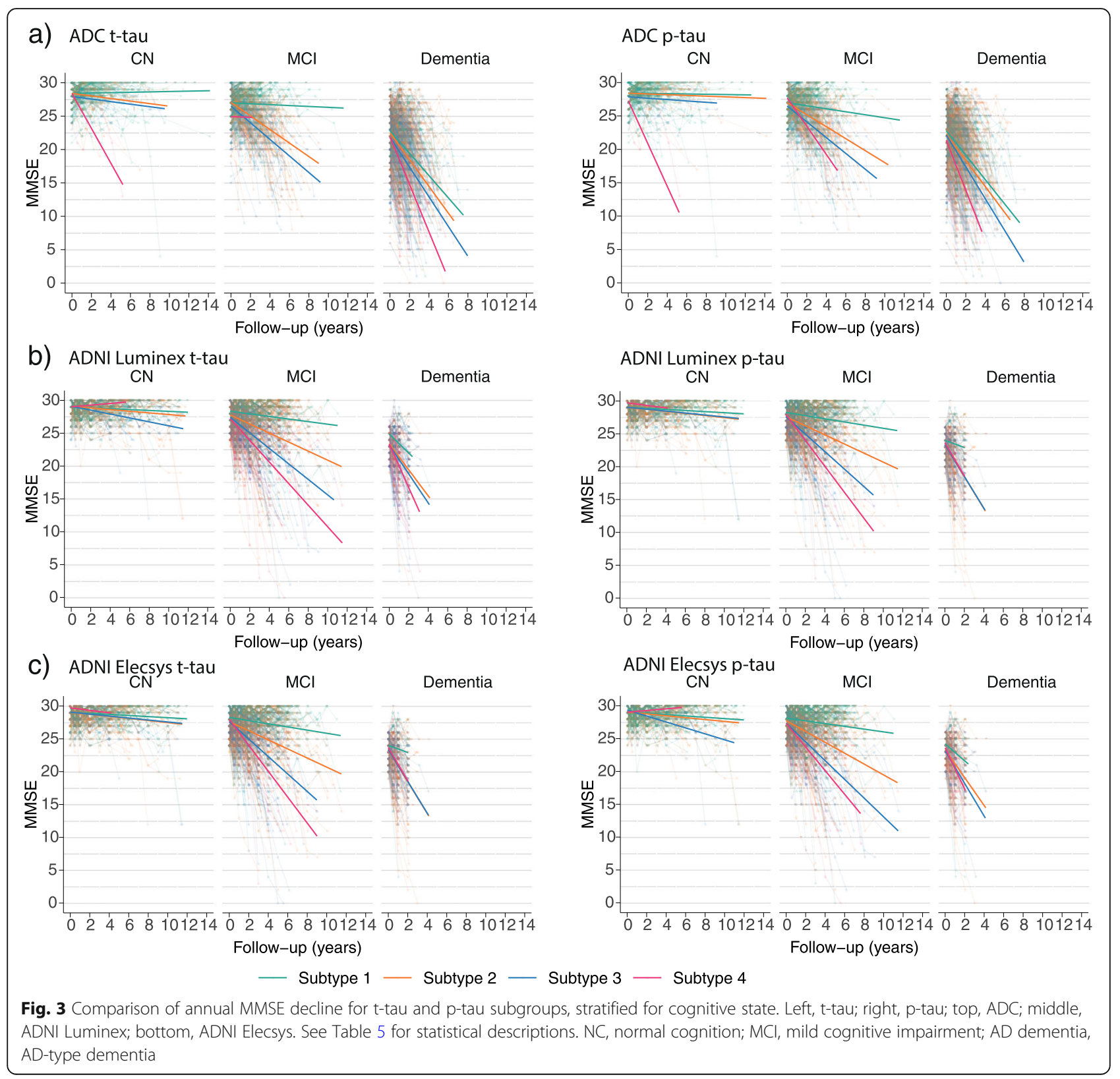




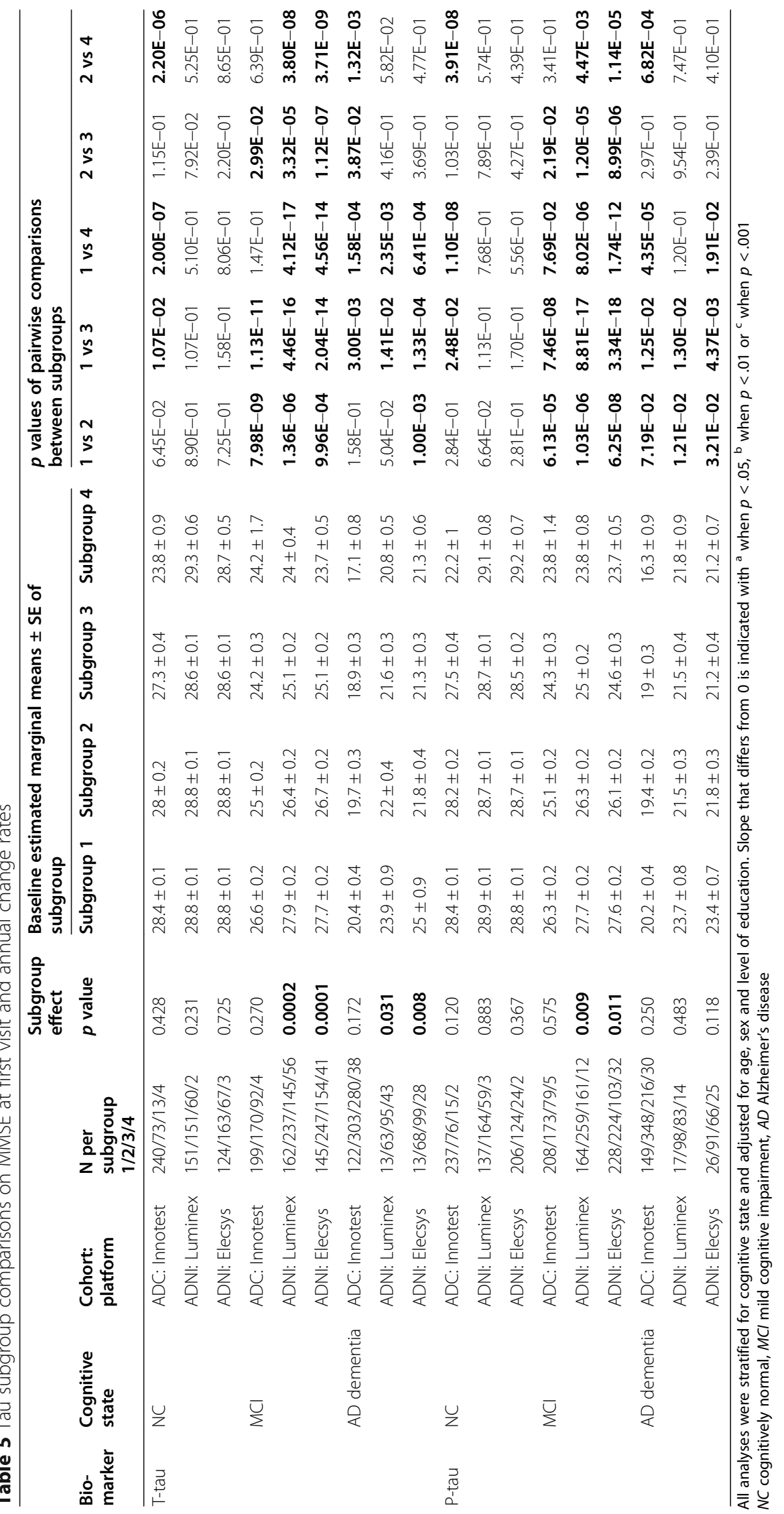




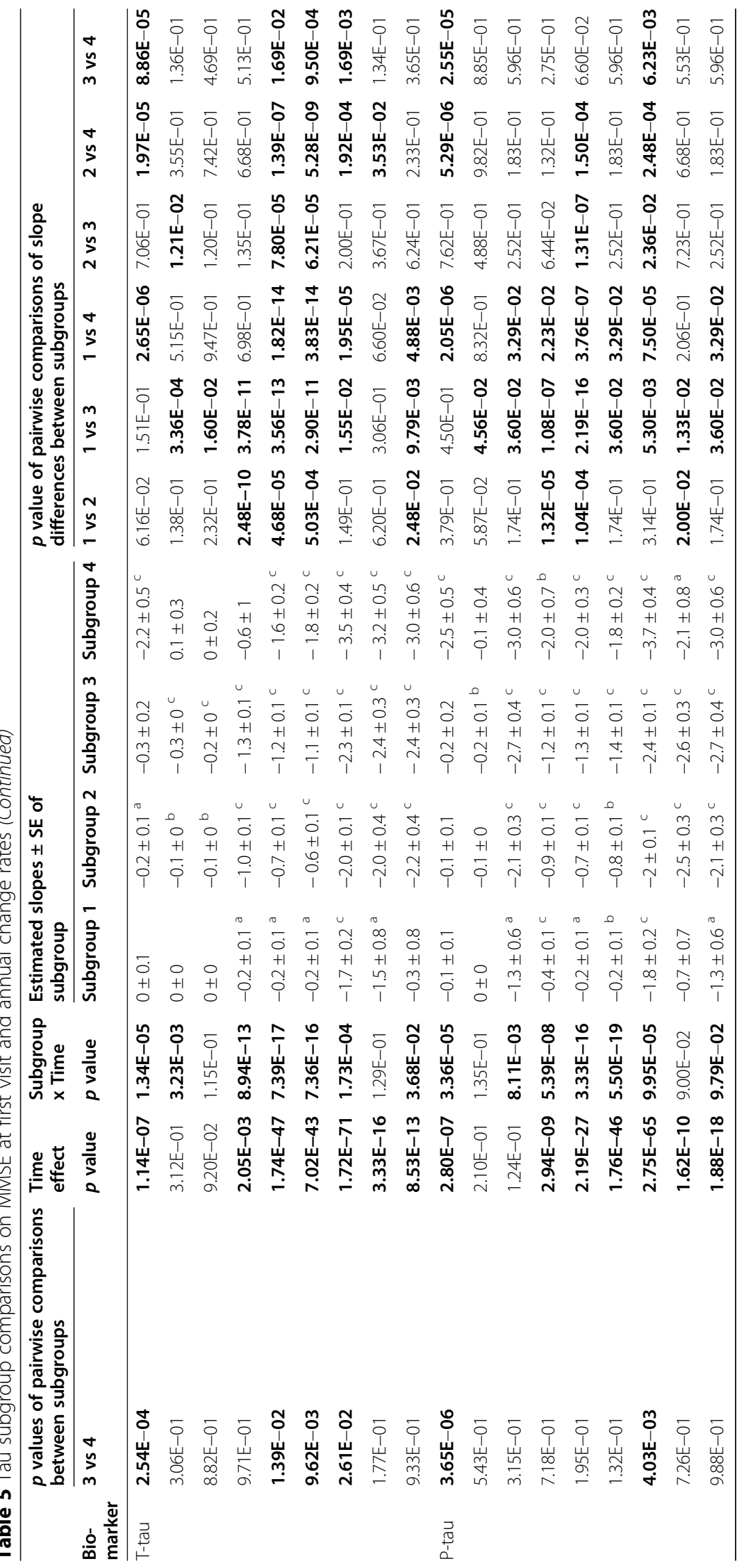


abnormal participants. This relationship also held for lower $\mathrm{t}$-tau values, with a higher prevalence of abnormal amyloid in the second subgroup than the lowest tau subgroup. $\mathrm{T}$ - and $\mathrm{p}$-tau subgroups were also associated with cognitive state, with lower subgroups containing the highest proportion of cognitively normal participants, while highest subgroups contained more demented participants (Table 3). Therefore, we stratified subsequent comparisons between tau subgroups for cognitive state. Average MMSE was lower for higher tau subgroups, with the strongest effects observed in AD-type dementia (Fig. 2; Table 3). Tau subgroups also differed in demographic factors, including age (on average lower in the lowest tau subgroup in $\mathrm{NC}$ and $\mathrm{MCI}$ ), sex (higher proportion of women in higher t-tau and p-tau subgroups), and APOE e4 carriership (higher prevalence in higher ttau and p-tau subgroups) (Fig. 2; Table 3). The associations of higher $\mathrm{t}$ - and $\mathrm{p}$-tau subgroups with amyloid, cognitive state, and demographic factors were mostly reproduced in ADNI.

\section{Rates of cognitive decline over time depend on tau subgroups}

We further studied whether subjects across tau subgroups differed in rates of cognitive decline, as measured with the MMSE stratified for cognitive state. In ADC, tau subgroups were not associated with cognitive decline in MCI or NC; however, in the dementia phase, higher tau subgroups were characterized by faster cognitive decline on MMSE (Fig. 3; Table 4). In ADNI, faster MMSE decline with higher tau subgroups in dementia was reproduced. While in ADC no association between tau subgroups and MMSE decline was found for participants

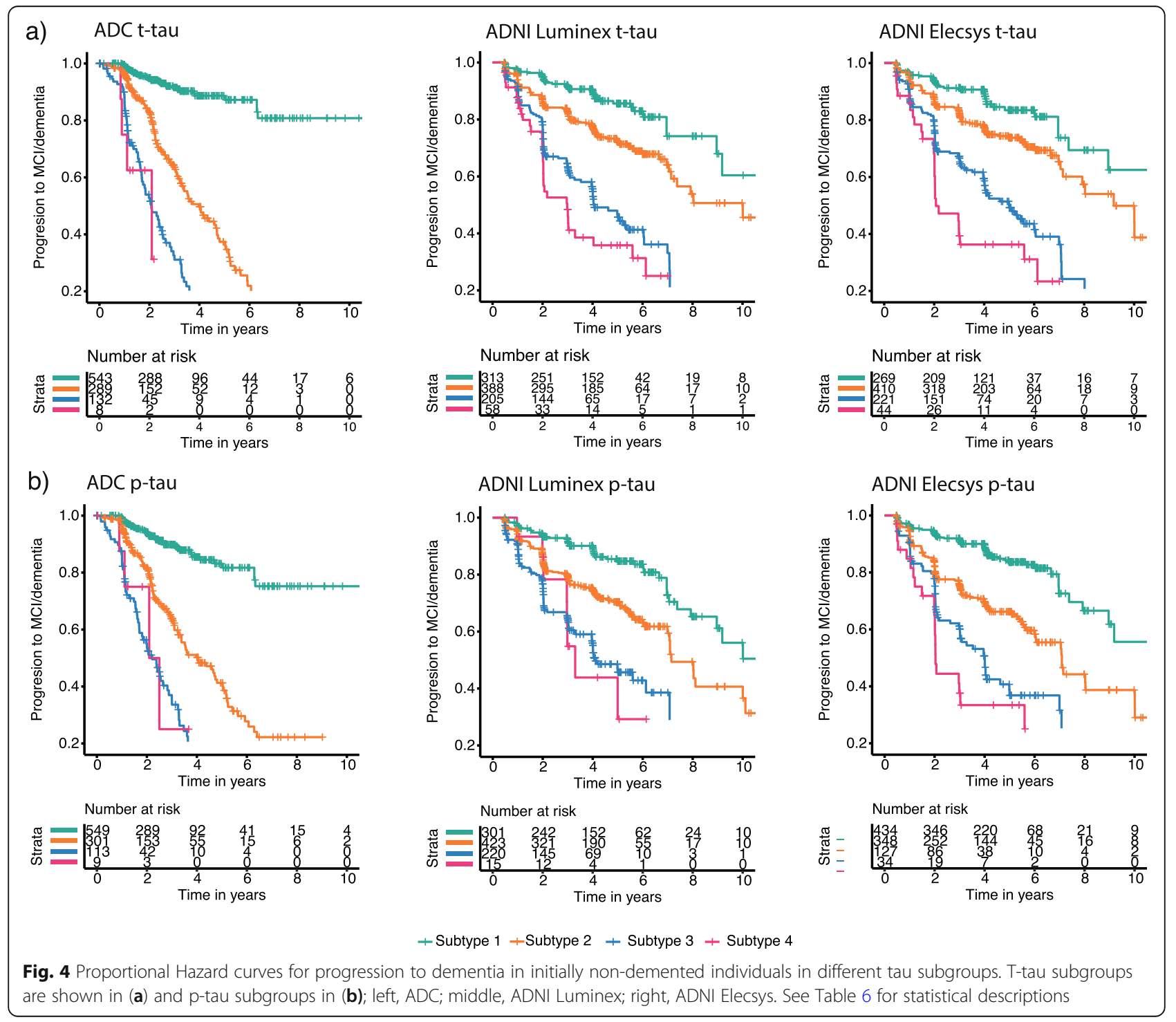




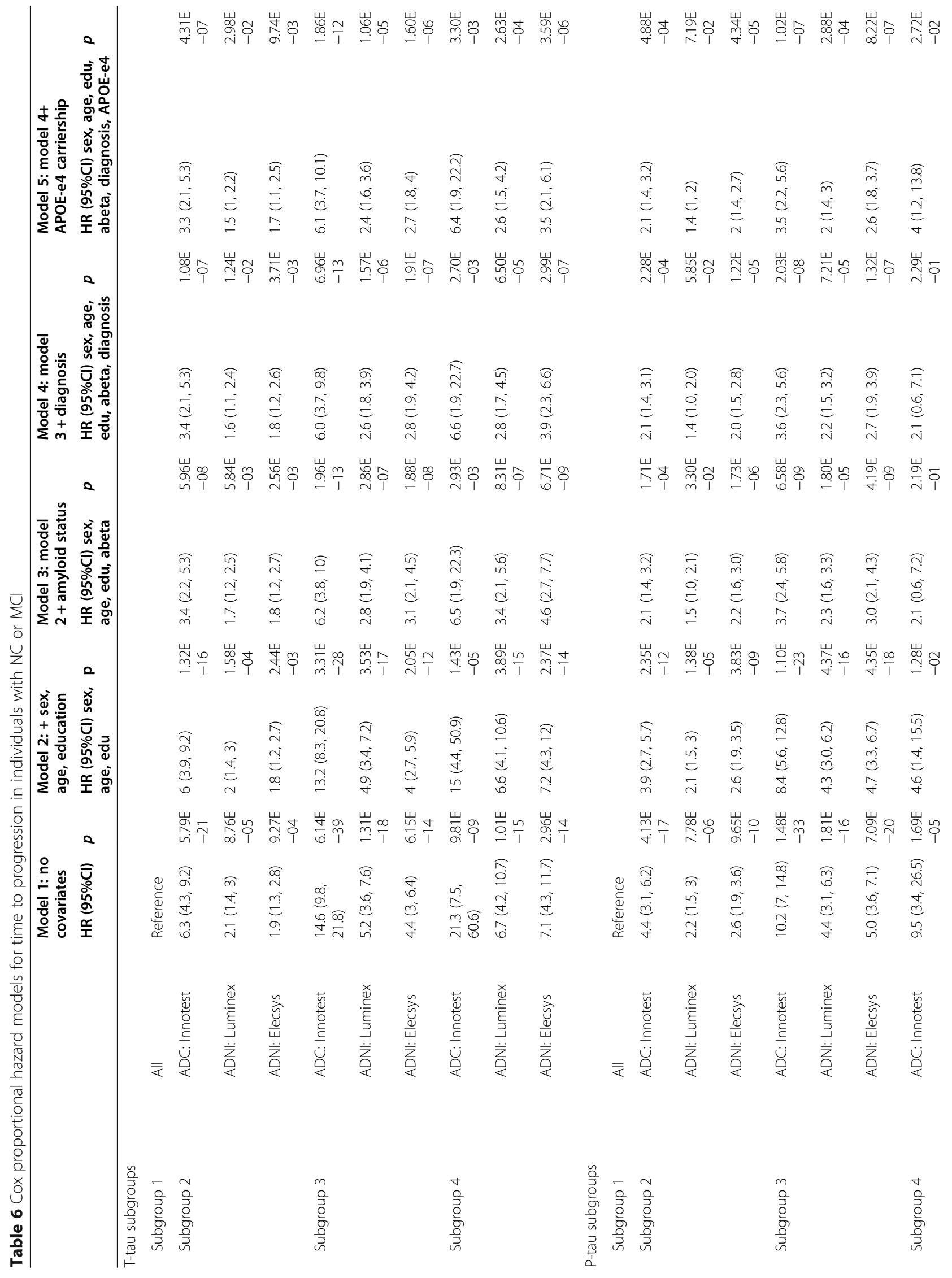




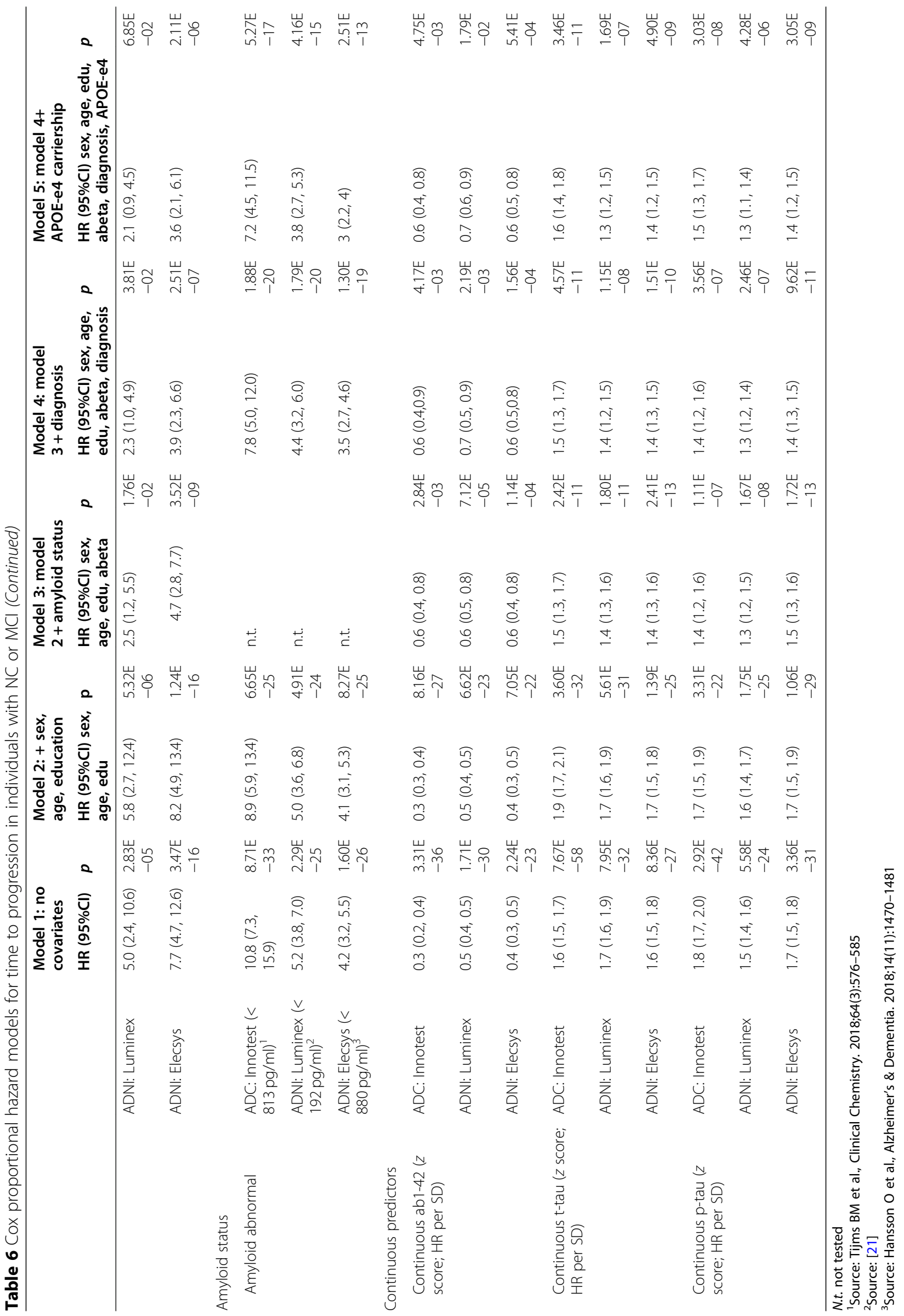


Table 7 Frequencies of individuals remaining or changing subgroup over time from baseline (rows)

\begin{tabular}{|c|c|c|c|c|c|}
\hline \multicolumn{2}{|c|}{ Biomarker: Platform } & \multicolumn{4}{|c|}{$\begin{array}{l}\text { Subgroup at last } \\
\text { measurement }\end{array}$} \\
\hline \multirow[t]{5}{*}{ T-tau: Luminex } & Baseline subgroup & 1 & 2 & 3 & 4 \\
\hline & 1 & 110 & 35 & 1 & 0 \\
\hline & 2 & 22 & 188 & 42 & 0 \\
\hline & 3 & 0 & 18 & 139 & 15 \\
\hline & 4 & 0 & 1 & 13 & 35 \\
\hline \multirow[t]{5}{*}{ T-tau: Elecsys } & Baseline subgroup & 1 & 2 & 3 & 4 \\
\hline & 1 & 92 & 25 & 1 & 0 \\
\hline & 2 & 11 & 206 & 36 & 0 \\
\hline & 3 & 0 & 17 & 147 & 13 \\
\hline & 4 & 0 & 1 & 4 & 33 \\
\hline \multirow[t]{5}{*}{ P-tau: Luminex } & Baseline subgroup & 1 & 2 & 3 & 4 \\
\hline & 1 & 103 & 63 & 11 & 0 \\
\hline & 2 & 24 & 164 & 91 & 5 \\
\hline & 3 & 2 & 23 & 100 & 13 \\
\hline & 4 & 0 & 1 & 6 & 6 \\
\hline \multirow[t]{5}{*}{ P-tau: Elecsys } & Baseline subgroup & 1 & 2 & 3 & 4 \\
\hline & 1 & 185 & 33 & 0 & 0 \\
\hline & 2 & 9 & 197 & 25 & 0 \\
\hline & 3 & 0 & 14 & 75 & 12 \\
\hline & 4 & 0 & 0 & 4 & 33 \\
\hline
\end{tabular}

with $\mathrm{MCI}$, in ADNI, higher tau subgroups in $\mathrm{MCI}$ were associated with MMSE decline (Table 5).

Next, we tested for individuals without dementia (i.e. $\mathrm{NC}$ and MCI) whether tau-subgroups differed in terms of progression to $\mathrm{MCI}$ or $\mathrm{AD}$-type dementia. In the ADC, 46/381 (12\%) of NC patients showed clinical progression either to MCI $(n=39)$ within $2.3 \pm 1.6$ years or to AD-type dementia $(n=16)$ in $4.5 \pm 4.0$ years, and 178 / 591 (30\%) of MCI patients progressed to AD-type dementia in $2.4 \pm 1.6$ years. Across the total group of nondemented subjects, hazard ratios (HRs) increased with increasing tau or $\mathrm{p}$-tau subgroups compared to the lowest tau or p-tau subgroups (Fig. 4; Table 6). Repeating analyses including covariates sex, age and education level (model 2), amyloid status (model 3), baseline cognitive state (model 4) and APOE-e4 carriership (model 5) generated largely similar results for $\mathrm{t}$-tau subgroups, although HRs were somewhat attenuated. Results were largely consistent for ADNI albeit with somewhat lower HR values (Table 6), where 65/371 (17.5\%) NC showed clinical progression either to MCI $(n=47)$ within $3 \pm 9$ years or to AD-type dementia $(n=18)$ in $8 \pm 3$ years, and 212/622 (34\%) MCI individuals to AD-type dementia in $4.1 \pm 2.3$ years. Of note is that in ADNI, individuals in the second Luminex $t$-tau subgroup had levels below the official cut-point defined by ADNI (i.e. $93 \mathrm{pg} / \mathrm{ml}$ [21]) and still showed higher HRs for progression to AD-type dementia compared to the first tau subgroup (HR $(95 \% \mathrm{CI})=2.1(1.4,3.0), p<.001)$.

\section{Longitudinal changes in tau concentrations in ADNI}

Examining transitions over time to higher tau groups in ADNI, we observed that the majority of individuals for both Luminex and Elecsys t-tau subgroups remained in the same subgroup as first measured (Luminex: 472 (76\% of 619); Elecsys: 443 (76\% of 586); Table 7; see Table 8 and Fig. 5 for continuous results). Of individuals who changed, the majority shifted to one tau group higher (Table 8).

\section{Comparison with tau PET in ADNI}

Finally, we compared CSF tau subgroups on tau PET uptake values available for 345 individuals (235 NC; 93 MCI; 28 dementia; of note, these included $n=232$ new CSF observations not included in mixture analyses). Figure 6 shows that tau PET uptake increased with higher $\mathrm{t}$-tau and p-tau subgroups. For all Braak regions, the uptake of the highest two tau subgroups was significantly higher than the lowest two (or three) subgroups (Table 9). The second lowest t-tau subgroup also showed higher average tau uptake in Braak I/II brain areas compared to subgroup 1, and the second lowest ptau subgroup in addition also to Braak III/IV and V/VI compared to subgroup 1 .

\section{Discussion}

In this study, we used Gaussian mixture modelling to determine unbiased cut-points for CSF tau levels. We identified three cut-points resulting in four different distributions, and the cut-point between the lowest two subgroups corresponded closely to an existing clinically defined cut-point [21]. Furthermore, two additional tau groups with highest $\mathrm{t}$ - and p-tau levels were discovered in the data. We similarly observed four distributions in the independent ADNI cohort, and despite differences between ADC and ADNI in cohort composition, tau subgroups showed similar clinical and biological characteristics in both study cohorts. These findings suggest that $\mathrm{t}$-tau and p-tau levels may not necessarily reflect disease stage, but possibly different biological subtypes of AD.

Tau is an intracellular protein playing an important role in microtubule assembly and stabilization in axons [24]. Hyperphosphorylation disturbs its function, resulting in the formation of aggregates or neurofibrillary tangles, which is one of the hallmarks of $\mathrm{AD}$ pathology. Still, the precise factors influencing $\mathrm{t}$ - and $\mathrm{p}$-tau CSF levels remain unclear. Measures correlated highly, and even though subgroup labelling showed moderate concordance, t-tau and p-tau subgroups showed similar 


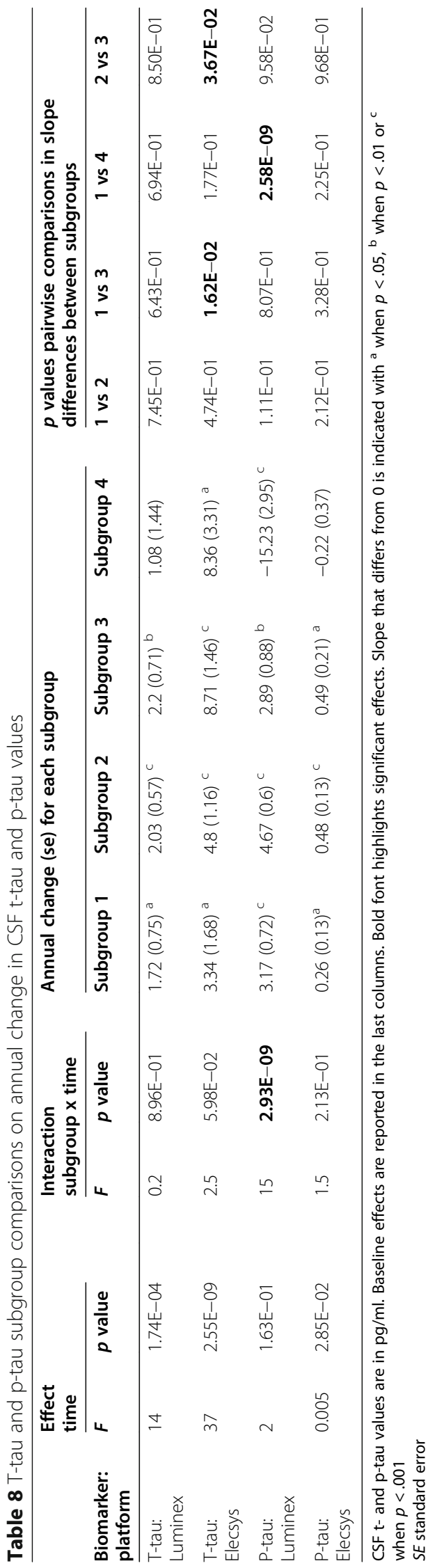




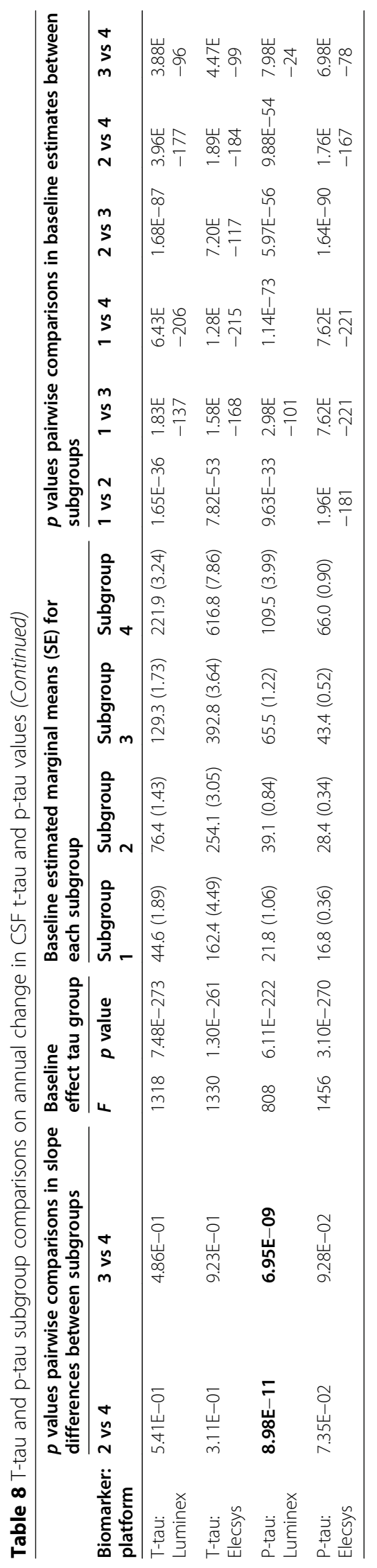




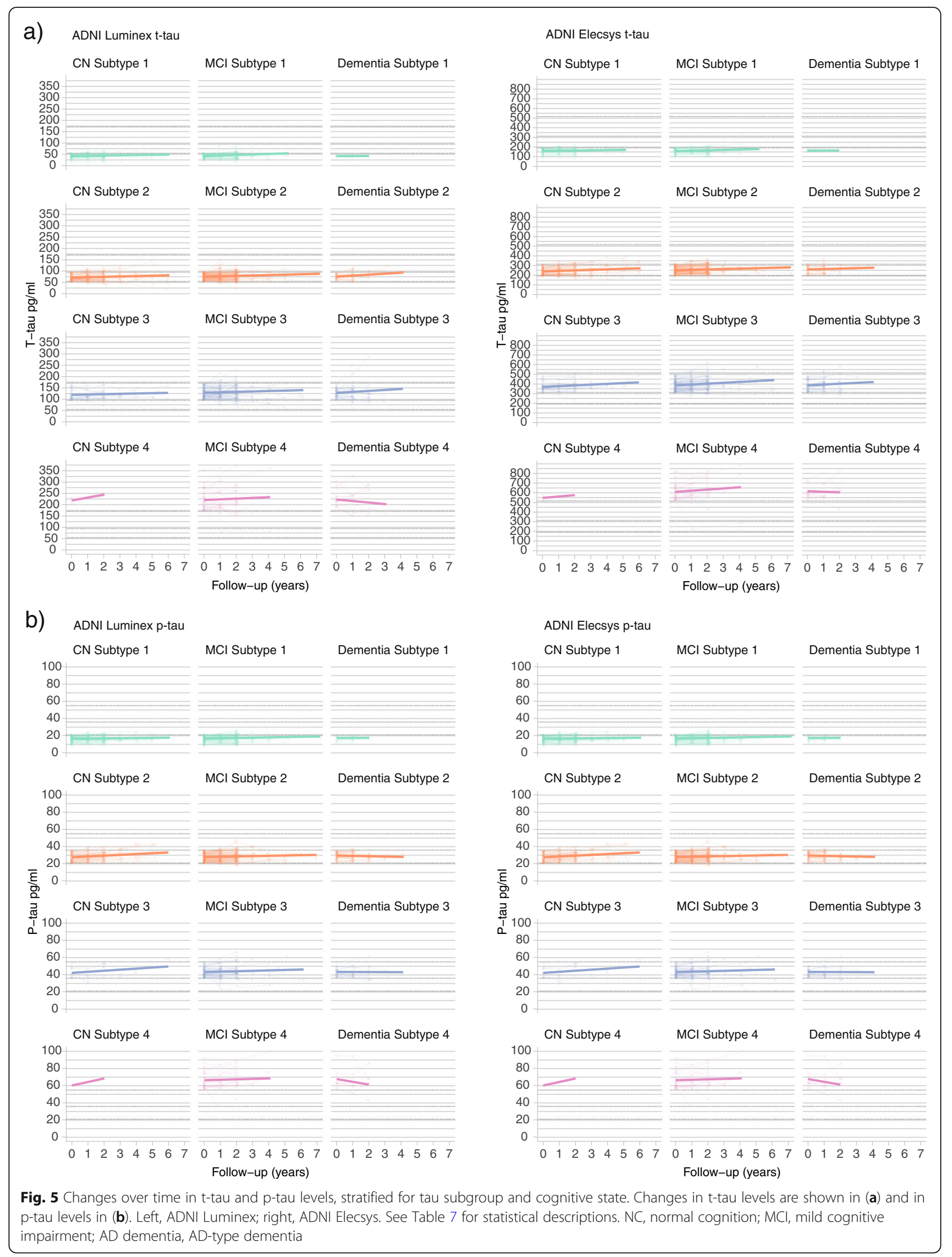




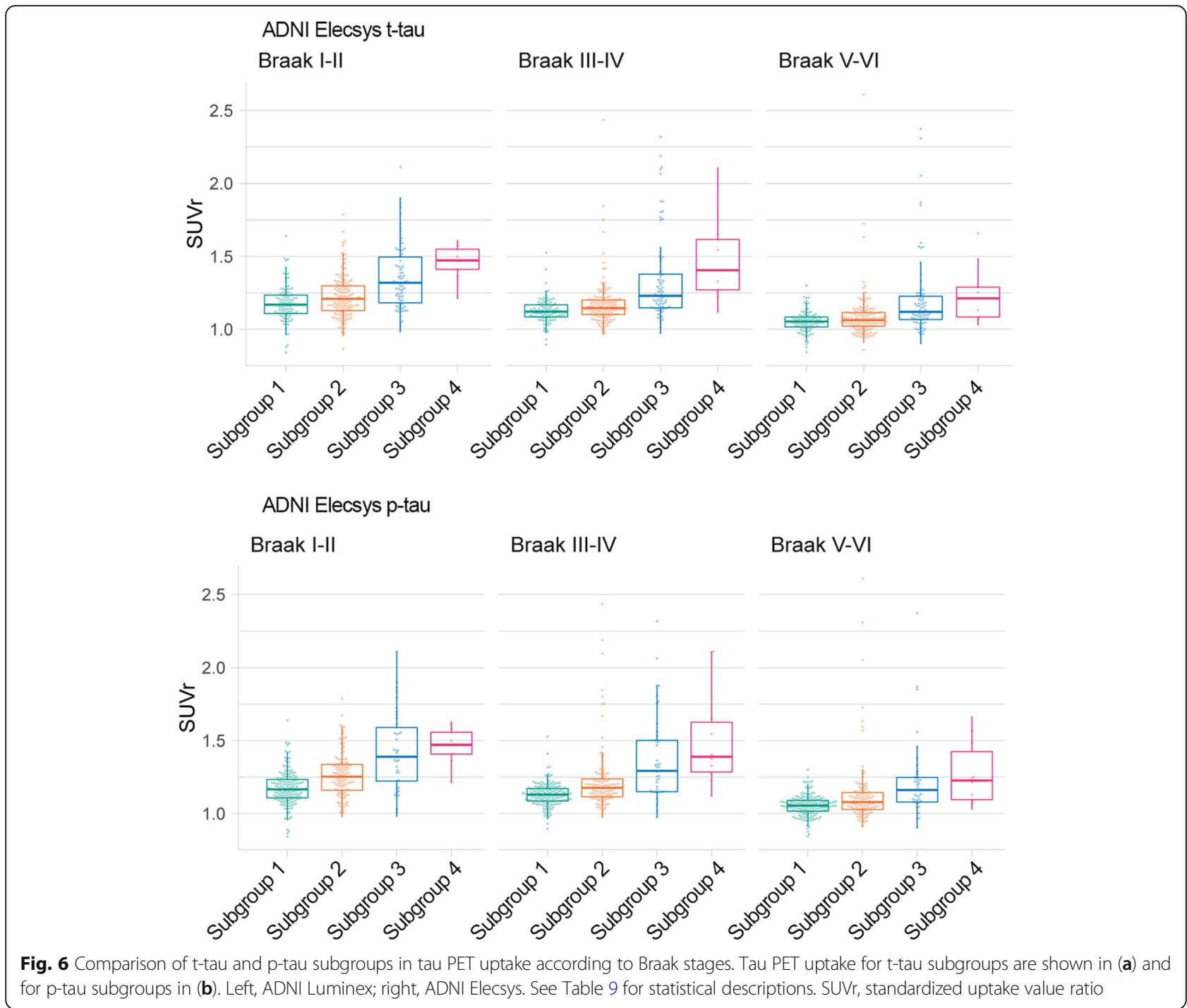

Table 9 T-tau and p-tau subgroup comparison on tau PET uptake

\begin{tabular}{|c|c|c|c|c|c|c|c|c|c|c|c|c|c|}
\hline \multirow[b]{2}{*}{$\begin{array}{l}\text { Tau PET } \\
\text { sUVr }\end{array}$} & \multirow[b]{2}{*}{ Subgroup } & \multicolumn{2}{|c|}{$\begin{array}{l}\text { T-tau } \\
\text { subgroup } \\
\text { effect }\end{array}$} & \multicolumn{4}{|c|}{ T-tau subgroup estimated marginal means (SE) } & \multicolumn{6}{|c|}{ T-tau subgroup pairwise comparisons $p$ value } \\
\hline & & $F$ & $p$ value & $\begin{array}{l}\text { Subgroup } \\
1\end{array}$ & $\begin{array}{l}\text { Subgroup } \\
2\end{array}$ & $\begin{array}{l}\text { Subgroup } \\
3\end{array}$ & $\begin{array}{l}\text { Subgroup } \\
4\end{array}$ & 1 vs 2 & 1 vs 3 & 1 vs 4 & 2 vs 3 & 2 vs 4 & 3 vs 4 \\
\hline \multirow[t]{2}{*}{ Braak I/II } & T-tau & 28 & $\begin{array}{l}3.69 E \\
-16\end{array}$ & $1.18(0.016)$ & $1.22(0.013)$ & $1.36(0.018)$ & $1.51(0.052)$ & $\begin{array}{l}2.91 \mathrm{E} \\
-02\end{array}$ & $\begin{array}{l}1.91 \mathrm{E} \\
-12\end{array}$ & $\begin{array}{l}1.65 \mathrm{E} \\
-09\end{array}$ & $\begin{array}{l}8.36 \mathrm{E} \\
-09\end{array}$ & $\begin{array}{l}1.03 \mathrm{E} \\
-07\end{array}$ & $\begin{array}{l}4.78 \mathrm{E} \\
-03\end{array}$ \\
\hline & P-tau & 37.6 & $\begin{array}{l}5.14 \mathrm{E} \\
-21\end{array}$ & $1.18(0.012)$ & $1.27(0.014)$ & $1.43(0.024)$ & $1.47(0.049)$ & $\begin{array}{l}1.02 \mathrm{E} \\
-06\end{array}$ & $\begin{array}{l}1.97 \mathrm{E} \\
-18\end{array}$ & $\begin{array}{l}1.95 \mathrm{E} \\
-08\end{array}$ & $\begin{array}{l}3.40 \mathrm{E} \\
-08\end{array}$ & $\begin{array}{l}1.22 \mathrm{E} \\
-04\end{array}$ & 4.67E-01 \\
\hline \multirow[t]{2}{*}{ Braak III/IV } & T-tau & 30 & $\begin{array}{l}2.64 \mathrm{E} \\
-17\end{array}$ & $1.13(0.019)$ & $1.17(0.016)$ & $1.34(0.022)$ & $1.56(0.061)$ & $5.19 \mathrm{E}-02$ & $\begin{array}{l}2.98 \mathrm{E} \\
-12\end{array}$ & $\begin{array}{l}6.58 \mathrm{E} \\
-11\end{array}$ & $\begin{array}{l}3.73 \mathrm{E} \\
-09\end{array}$ & $\begin{array}{l}3.08 \mathrm{E} \\
-09\end{array}$ & $\begin{array}{l}7.24 \mathrm{E} \\
-04\end{array}$ \\
\hline & P-tau & 31 & $\begin{array}{l}1.04 \mathrm{E} \\
-17\end{array}$ & $1.13(0.014)$ & $1.23(0.017)$ & $1.38(0.029)$ & $1.51(0.059)$ & $\begin{array}{l}1.79 \mathrm{E} \\
-05\end{array}$ & $\begin{array}{l}1.50 \mathrm{E} \\
-13\end{array}$ & $\begin{array}{l}7.23 E \\
-10\end{array}$ & $\begin{array}{l}7.87 E \\
-06\end{array}$ & $\begin{array}{l}3.88 \mathrm{E} \\
-06\end{array}$ & $\begin{array}{l}4.08 \mathrm{E} \\
-02\end{array}$ \\
\hline \multirow[t]{2}{*}{ Braak VNI } & T-tau & 16 & $\begin{array}{l}7.49 \mathrm{E} \\
-10\end{array}$ & $1.05(0.018)$ & $1.09(0.015)$ & $1.21(0.021)$ & $1.32(0.058)$ & $1.50 \mathrm{E}-01$ & $\begin{array}{l}3.80 \mathrm{E} \\
-08\end{array}$ & $\begin{array}{l}1.01 \mathrm{E} \\
-05\end{array}$ & $\begin{array}{l}2.69 \mathrm{E} \\
-06\end{array}$ & $\begin{array}{l}8.12 \mathrm{E} \\
-05\end{array}$ & $5.80 \mathrm{E}-02$ \\
\hline & P-tau & 14.2 & $\begin{array}{l}1.04 \mathrm{E} \\
-08\end{array}$ & $1.06(0.014)$ & $1.13(0.016)$ & $1.22(0.028)$ & $1.27(0.056)$ & $\begin{array}{l}4.88 \mathrm{E} \\
-04\end{array}$ & $\begin{array}{l}1.21 \mathrm{E} \\
-07\end{array}$ & $\begin{array}{l}1.97 \mathrm{E} \\
-04\end{array}$ & $\begin{array}{l}4.22 \mathrm{E} \\
-03\end{array}$ & $\begin{array}{l}1.49 \mathrm{E} \\
-02\end{array}$ & 4.21E-01 \\
\hline
\end{tabular}


differences in tau PET uptake. Previous studies comparing CSF tau measures with tau PET have been inconsistent [25-27]. Together with our results, it remains unclear whether CSF t-tau and p-tau reflect similar or different aspects of neuronal injury. Higher levels of $\mathrm{t}-$ and p-tau might result from passive release into extracellular space due to neuronal death which increases with worse disease severity. However, tau is also actively secreted by neurons as part of normal physiology [28] and can increase in the presence of amyloid pathology [29]. The majority of individuals remained in their t-tau subgroup over time, suggesting that at least part of their levels do not depend on disease stage, but perhaps reflect other biological aspects. The relative lack of change over time in tau levels within individuals seems at odds with the idea that tau increases with worsening cognition. Previous longitudinal CSF studies have reported conflicting results, observing increases in middle-age individuals with normal cognition during a follow-up period of 6 years [30], but also a lack of change in individuals with normal cognition, $\mathrm{MCI}$ and $\mathrm{AD}$ over a median follow-up of 2 years [31, 32]. This literature together with our observations suggests that increases over time in t-tau levels in CSF are slow, and follow-up times longer than 2-3 years might be necessary for participants to change subgroups.

One of the challenges in biomarkers research is how to define the cut-point between normal and abnormal levels. Pathology is the gold standard, but is also the end stage of the disease and difficult to obtain for large sample sizes. The cut-point for Luminex p-tau in ADNI was originally based on pathology [21], and we observed the same cut-off for the lowest p-tau subgroup $(23 \mathrm{pg} / \mathrm{ml})$. However, for $\mathrm{t}$-tau, we observed a lower cut-off that was still related to increased risk for disease progression. A recent study defined cut-points for $\mathrm{t}$ - and $\mathrm{p}$-tau measured with Elecsys (t-tau $300 \mathrm{pg} / \mathrm{ml}$ and p-tau $27 \mathrm{pg} / \mathrm{ml}$ ) in ADNI based on their association with clinical progression in MCI patients [23]. We expand upon previous studies $[6,11,33,34]$ by identifying additional cutpoints that may have practical use for more specific prognoses to individual patients or in trial design: we identified lower cut-points than defined in the literature (resp. 193 and $22 \mathrm{pg} / \mathrm{ml}$ for $\mathrm{t}$ - and p-tau, respectively) that were already associated with increased risk for clinical progression, and also showed for the higher cutpoints, that the corresponding subgroups were associated with gradually increasing hazard ratios and steeper decline on the MMSE.

The notion that higher tau subgroups also included non-demented individuals, and that higher tau levels were associated with faster cognitive decline, regardless of disease stage, suggests that tau subgroups may reflect differences in underlying biological processes, rather than disease severity per se. This is supported by the observation that higher tau subgroups showed increasing proportions of APOE e4 carriers, the strongest genetic risk factor for $\mathrm{AD}$ [35]. Previous studies have also reported higher levels of tau in APOE-e4 carriers, also in predementia stages [36]; however, also see [37] where tau levels were similar between carriers and noncarriers. Other genetic risk factors may contribute to differences in tau levels as well, as another study reported that a polygenic risk score, including SNPs with moderate strength to detect $\mathrm{AD}$, was strongly related to $\mathrm{t}$-tau and p-tau levels, also after correcting for APOE [38]. This suggests that multiple genetic risk factors may explain variability between individual tau levels. More studies with large sample sizes are needed to further investigate these biological factors associated with tau levels in CSF. Also, future studies should further investigate the longitudinal relationship of these tau subtypes with concurrent other biological measures that deteriorate during the $\mathrm{AD}$ process, such as synaptic markers in CSF or on PET, and cognitive data, to better understand differences in clinical progression amongst tau subtypes.

\section{Limitations}

A potential limitation of our study is that although we used large clinical cohorts, the number of subjects in some subgroups and subanalyses was small: this was especially the case in the highest tau subgroup, as well as in tau PET analyses. The small size of the highest tau subgroup means that there is more uncertainty in the association of this subgroup with clinical characteristics. Therefore, the results regarding the highest tau subgroup and the tau PET analyses should be interpreted with caution, and if possible repeated in future studies in even larger cohorts. Furthermore, we used Gaussian mixtures as a data-driven approach to study potential subgroups in tau levels as a first step, it is possible that more complex models may improve the fit of tau levels distributions, which should be addressed in future studies. Also, we determined cut-points here as the intersections of the probability distributions of the normal mixtures, which may not be ideal in all settings. For example, in studies where minimizing misclassification costs is desired, e.g. in clinical trial design, it may be useful to choose cut-points so that misclassification is minimized of individuals with high tau as falling in the lowest tau group, to ensure that as many individuals with potentially fast progression are included in the trial. Future studies could test the efficacy of the data-driven cut-points in those settings. Strengths of the study are that we used a large cohort, and we validated the mixture modelling results in another independent cohort with two different analysis platforms for CSF tau, and both cohorts had detailed information of the 
characteristics of the study populations, including cognitive measures, follow-up data on clinical progression and information on APOE genotype available.

\section{Conclusions}

In conclusion, our studies suggest that abnormal levels of CSF t-tau and p-tau may convey different biological aspects in $\mathrm{AD}$, which might be in part driven by genetic factors such as different APOE genotypes. The data-driven cutpoints we found may aid daily practice in prognosis of patients and may aid trial design by allowing stratification of individuals according to their risk of clinical progression.

\section{Supplementary information}

Supplementary information accompanies this paper at https://doi.org/10. 1186/s13195-020-00713-3.

\section{Additional file 1.}

Additional file 2

\section{Abbreviations}

A 342 : Amyloid- $\beta$ 1-42; AD: Alzheimer's disease; ADC: Amsterdam Dementia Cohort; ADNI: Alzheimer's disease Neuroimaging Initiative; APOE: Apolipoprotein E; Cl: Confidence interval; CSF: Cerebrospinal fluid; HR: Hazard ratio; NC: Normal cognition; MCl: Mild cognitive impairment; MMSE: Mini-Mental State Examination; MRI: Magnetic resonance imaging; PET: Positron emission tomography; p-tau-181: Tau phosphorylated at threonine 181; t-tau: Total tau

\begin{abstract}
Acknowledgements
Data was used for this project of which collection and sharing was funded by the Alzheimer's Disease Neuroimaging Initiative (ADNI) (National Institutes of Health Grant U01 AG024904) and DOD ADNI (Department of Defense award number W81XWH-12-2-0012). ADNI is funded by the National Institute on Aging, the National Institute of Biomedical Imaging and Bioengineering, and through generous contributions from the following: AbbVie, Alzheimer's Association; Alzheimer's Drug Discovery Foundation; Araclon Biotech; BioClinica, Inc.; Biogen; Bristol-Myers Squibb Company; CereSpir, Inc.; Cogstate; Eisai Inc.; Elan Pharmaceuticals, Inc.; Eli Lilly and Company; Eurolmmun; F. Hoffmann-La Roche Ltd. and its affiliated company Genentech, Inc.; Fujirebio; GE Healthcare; IXICO Ltd.; Janssen Alzheimer Immunotherapy Research \& Development, LLC.; Johnson \& Johnson Pharmaceutical Research \& Development LLC.; Lumosity; Lundbeck; Merck \& Co., Inc.; Meso Scale Diagnostics, LLC.; NeuroRx Research; Neurotrack Technologies; Novartis Pharmaceuticals Corporation; Pfizer Inc.; Piramal Imaging; Servier; Takeda Pharmaceutical Company; and Transition Therapeutics. The Canadian Institutes of Health Research is providing funds to support ADNI clinical sites in Canada. Private sector contributions are facilitated by the Foundation for the National Institutes of Health (www.fnih.org). The grantee organization is the Northern California Institute for Research and Education, and the study is coordinated by the Alzheimer's Therapeutic Research Institute at the University of Southern California. ADNI data are disseminated by the Laboratory for Neuro Imaging at the University of Southern California.

Part of the data used in preparation of this article were obtained from the Alzheimer's Disease Neuroimaging Initiative (ADNI) database (adni.loni.usc. edu). As such, the investigators within the ADNI contributed to the design and implementation of ADNI and/or provided data but did not participate in analysis or writing of this report. A complete listing of ADNI investigators can be found at: http://adni.loni.usc.edu/wp-content/uploads/how_to_apply/ ADNI_Acknowledgement_List.pdf
\end{abstract}

\section{Authors' contributions}

FD wrote the first drafts of the manuscript; KW and BT contributed further revisions. FD and $B T$ performed the statistical analyses. LE contributed to the writing of the discussion. EWo contributed to methods and discussion related to PET imaging. PS and WF led the design and set-up of the ADC, from which data were used in this article. LE, EWo, EWi, WF, BT, CT and PV made suggestions on improvement of the manuscript. All authors read and approved the manuscript for submission.

\section{Funding}

This work has been supported by ZonMW Memorabel grant programme \#733050824 (KW, BMT and PJV), Alzheimer Nederland grant \#NL18003P (FD) and the Sigrid Juselius Foundation (LE). Funding was used in the analysis, interpretation and writing of the manuscript. Statistical analyses were performed at the VUmc Alzheimer Center that is part of the neurodegeneration research programme of the Neuroscience Campus Amsterdam. The VUmc Alzheimer Center is supported by Stichting Alzheimer Nederland and Stichting VUmc fonds.

\section{Availability of data and materials}

The ADNI dataset analysed during the current study is available in the ADNI repository, www.adni-info.org. For ADC, the data that support the findings of this study are available from the corresponding author upon reasonable request.

\section{Ethics approval and consent to participate}

The institutional review boards of all institutions participating in ADNI approved the procedures that were part of the study. For ADC, all procedures were approved by the local medical ethics committee. In both ADNI and ADC, written informed consent was obtained from all participants or surrogates.

\section{Consent for publication}

Not applicable.

\section{Competing interests}

Prof. dr. Scheltens has acquired grants for the institution from GE Healthcare and Piramal and received consultancy/speaker fees paid to the institution from Novartis, Probiodrug, Biogen, Roche, and EIP Pharma, LLC in the past 2 years. Research programmes of Prof. dr. Wiesje van der Flier received funding by ZonMW, NWO, EU-JPND, Alzheimer Nederland, CardioVascular Onderzoek Nederland, Health Holland, Topsector Life Sciences \& Health, stichting Dioraphte, Gieskes-Strijbis fonds, stichting Equilibrio, Biogen MA Inc., Life-MI, AVID, Combinostics. WF holds the Pasman chair. WF has performed contract research for Biogen MA Inc. All funding is paid to her institution. Prof. dr. Teunissen received grants from the European Commission, the Dutch Research Council (ZonMW), Association of Frontotemporal Dementia/Alzheimer's Drug Discovery Foundation, The Weston Brain Institute, Alzheimer Netherlands. Prof. Dr. Teunissen has functioned in advisory boards of Roche, received non-financial support in the form of research consumables from ADxNeurosciences and Euroimmun, performed contract research or received grants from Probiodrug, Biogen, Esai, Toyama, Janssen Prevention Center, Boehringer, AxonNeurosciences, EIP farma, PeopleBio, Roche. The other authors reported no conflicts of interest.

\section{Author details}

'Department of Neurology, Alzheimer Center Amsterdam, Amsterdam Neuroscience, Vrije Universiteit Amsterdam, Amsterdam UMC, Amsterdam, the Netherlands. ${ }^{2}$ Turku PET Centre, University of Turku and Turku University Hospital, Turku, Finland. ${ }^{3}$ Department of Radiology \& Nuclear Medicine, Amsterdam Neuroscience, Amsterdam UMC, Amsterdam Neuroscience, Amsterdam, Netherlands. ${ }^{4}$ Department of Clinical Chemistry, Neurochemistry Laboratory, Amsterdam UMC, Amsterdam Neuroscience, Amsterdam, Netherlands. ${ }^{5}$ Department of Epidemiology and Biostatistics, Amsterdam UMC, Amsterdam, The Netherlands. ${ }^{6}$ Alzheimer Center Limburg, Department of Psychiatry \& Neuropsychology, School of Mental Health and Neuroscience, Maastricht University, Maastricht, The Netherlands. ${ }^{7}$ Division of Neurogeriatrics, Department of Neurobiology, Care Sciences and Society, Karolinska Institutet, Stockholm, Sweden.

Received: 16 June 2020 Accepted: 22 October 2020 Published online: 04 January 2021

\section{References}

1. Olsson B, Lautner R, Andreasson U, Öhrfelt A, Portelius E, Bjerke M, et al. CSF and blood biomarkers for the diagnosis of Alzheimer's disease: a systematic 
review and meta-analysis. Lancet Neurol. 2016;15:673-84 https://doi.org/10. 1016/S1474-4422(16)00070-3.

2. McKhann GM, Knopman DS, Chertkow H, Hyman BT, Jack CR, Kawas CH, et al. The diagnosis of dementia due to Alzheimer's disease: recommendations from the National Institute on Aging-Alzheimer's Association workgroups on diagnostic guidelines for Alzheimer's disease. Alzheimers Dement. 2011; 7:263-9 https://doi.org/10.1016/J.JALZ.2011.03.005.

3. Dubois B, Feldman HH, Jacova C, Hampel H, Molinuevo JL, Blennow K, et al. Advancing research diagnostic criteria for Alzheimer's disease: the IWG-2 criteria. Lancet Neurol. 2014;13:614-29 https://doi.org/10.1016/S14744422(14)70090-0.

4. Mattsson N, Zetterberg H, Hansson O, Andreasen N, Parnetti L, Jonsson M, et al. CSF biomarkers and incipient Alzheimer disease in patients with mild cognitive impairment. JAMA. 2009;302:385 https://doi.org/10.1001/jama. 2009.1064.

5. Mulder C, Verwey NA, van der Flier WM, Bouwman FH, Kok A, van Elk EJ, et al. Amyloid- (1-42), total tau, and phosphorylated tau as cerebrospinal fluid biomarkers for the diagnosis of Alzheimer disease. Clin Chem. 2010;56:24853 https://doi.org/10.1373/clinchem.2009.130518.

6. Duits FH, Teunissen CE, Bouwman FH, Visser P-J, Mattsson N, Zetterberg H, et al. The cerebrospinal fluid "Alzheimer profile": easily said, but what does it mean? Alzheimer's Dement. 2014;10:713-23.e2 https://doi.org/10.1016/J. JALZ.2013.12.023.

7. Toledo JB, Zetterberg H, van Harten AC, Glodzik L, Martinez-Lage P, Bocchio-Chiavetto $L$, et al. Alzheimer's disease cerebrospinal fluid biomarker in cognitively normal subjects. Brain. 2015;138:2701-15 https://doi.org/10. 1093/brain/awv199.

8. Mirra SS. The CERAD neuropathology protocol and consensus recommendations for the postmortem diagnosis of Alzheimer's disease: a commentary. Neurobiol Aging. 184 Suppl:S91-4. http://www.ncbi.nlm.nih. gov/pubmed/9330994. Accessed 9 Sept 2019

9. Knopman DS, DeKosky ST, Cummings JL, Chui H, Corey-Bloom J, Relkin N, et al. Practice parameter: diagnosis of dementia (an evidence-based review): report of the Quality Standards Subcommittee of the American Academy of Neurology. Neurology. 2001;56:1143-53 https://doi.org/10.1212 WNL.56.9.1143.

10. Beach TG, Monsell SE, Phillips LE, Kukull W. Accuracy of the clinical diagnosis of Alzheimer disease at National Institute on Aging Alzheimer Disease Centers, 2005-2010. J Neuropathol Exp Neurol. 2012;71:266-73 https://doi. org/10.1097/NEN.0b013e31824b211b.

11. Degerman Gunnarsson M, Ingelsson M, Blennow K, Basun H, Lannfelt L, Kilander L. High tau levels in cerebrospinal fluid predict nursing home placement and rapid progression in Alzheimer's disease. Alzheimers Res Ther. 2016:8:22 https://doi.org/10.1186/s13195-016-0191-0.

12. De Meyer G, Shapiro F, Vanderstichele H, Vanmechelen E, Engelborghs S, De Deyn PP, et al. Diagnosis-independent Alzheimer disease biomarker signature in cognitively normal elderly people. Arch Neurol. 2010;67:949 https://doi.org/10.1001/archneurol.2010.179.

13. Bertens D, Tijms BM, Scheltens P, Teunissen CE, Visser PJ. Unbiased estimates of cerebrospinal fluid $\beta$-amyloid 1-42 cutoffs in a large memory clinic population. Alzheimers Res Ther. 2017;9:8 https://doi.org/10.1186/ s13195-016-0233-7.

14. Zwan M, van Harten A, Ossenkoppele R, Bouwman F, Teunissen C, Adriaanse $\mathrm{S}$, et al. Concordance between cerebrospinal fluid biomarkers and [11C] PIB PET in a memory clinic cohort. J Alzheimers Dis. 2014;41:801-7 https://doi.org/10.3233/JAD-132561.

15. Zwan MD, Rinne JO, Hasselbalch SG, Nordberg A, Lleó A, Herukka S-K, et al. Use of amyloid-PET to determine cutpoints for CSF markers. Neurology. 2016;86:50-8 https://doi.org/10.1212/WNL.0000000000002081.

16. Palmqvist $\mathrm{S}$, Zetterberg $\mathrm{H}$, Blennow K, Vestberg S, Andreasson U, Brooks DJ, et al. Accuracy of brain amyloid detection in clinical practice using cerebrospinal fluid $\beta$-amyloid 42. JAMA Neurol. 2014;71:1282 https://doi.org/ 10.1001/jamaneurol.2014.1358.

17. Blennow K, Hampel H. CSF markers for incipient Alzheimer's disease. Lancet Neurol. 2003;2:605-13.

18. Blennow K, Hampel H, Weiner M, Zetterberg H. Cerebrospinal fluid and plasma biomarkers in Alzheimer disease. Nat Rev Neurol. 2010;6:131-44.

19. van der Flier WM, Scheltens P. Amsterdam dementia cohort: performing research to optimize care. J Alzheimers Dis. 2018;62:1091-111 https://doi. org/10.3233/JAD-170850.

20. Jongbloed W, Kester MI, van der Flier WM, Veerhuis R, Scheltens $P$, Blankenstein MA, et al. Discriminatory and predictive capabilities of enzyme- linked immunosorbent assay and multiplex platforms in a longitudinal Alzheimer's disease study. Alzheimers Dement. 2013;9:276-83 https://doi. org/10.1016/j.jalz.2012.01.004

21. Shaw LM, Vanderstichele H, Knapik-Czajka M, Clark CM, Aisen PS, Petersen $\mathrm{RC}$, et al. Cerebrospinal fluid biomarker signature in Alzheimer's disease neuroimaging initiative subjects. Ann Neurol. 2009;65:403-13 https://doi. org/10.1002/ana.21610.

22. Verhage F. Intelligentie en Leeftijd: Onderzoek bij Nederlanders van Twaalf tot Zevenenzeventig Jaar [Intelligence and Age: Study with Dutch People from Age 12 to 77]. Assen: Van Gorcum; 1964.

23. Blennow K, Shaw LM, Stomrud E, Mattsson N, Toledo JB, Buck K, et al. Predicting clinical decline and conversion to Alzheimer's disease or dementia using novel Elecsys A $\beta$ (1-42), pTau and tTau CSF immunoassays. Sci Rep. 2019;9:19024 https://doi.org/10.1038/s41598-019-54204-z.

24. Iqbal K, Liu F, Gong C-X. Tau and neurodegenerative disease: the story so far. Nat Rev Neurol. 2016;12:15-27 https://doi.org/10.1038/nrneurol.2015.225.

25. Chhatwal JP, Schultz AP, Marshall GA, Boot B, Gomez-Isla T, Dumurgier J, et al. Temporal T807 binding correlates with CSF tau and phospho-tau in normal elderly. Neurology. 2016;87:920-6.

26. Mattsson N, Schöll M, Strandberg O, Smith R, Palmqvist S, Insel PS, et al. 18 F-AV-1451 and CSF T-tau and P-tau as biomarkers in Alzheimer's disease. EMBO Mol Med. 2017;9:1212-23.

27. Gordon BA, Friedrichsen K, Brier M, Blazey T, Su Y, Christensen J, et al. The relationship between cerebrospinal fluid markers of Alzheimer pathology and positron emission tomography tau imaging. Brain. 2016;139:2249-60.

28. Pooler AM, Phillips EC, Lau DHW, Noble W, Hanger DP. EMBO Reports. 2013; 14(4):389-94. https://doi.org/10.1038/embor.2013.15.

29. Sato C, Barthélemy NR, Mawuenyega KG, Patterson BW, Gordon BA, JockelBalsarotti J, et al. Tau kinetics in neurons and the human central nervous system. Neuron. 2018;97:1284-98.e7 https://doi.org/10.1016/j.neuron.2018. 02.015.

30. Sutphen $\mathrm{CL}$, Jasielec MS, Shah AR, Macy EM, Xiong C, Vlassenko AG, et al. Longitudinal cerebrospinal fluid biomarker changes in preclinical Alzheimer disease during middle age. JAMA Neurol. 2015;72:1029 https://doi.org/10. 1001/jamaneurol.2015.1285.

31. Lleó A, Alcolea D, Martínez-Lage P, Scheltens P, Parnetti L, Poirier J, et al. Longitudinal cerebrospinal fluid biomarker trajectories along the Alzheimer's disease continuum in the BIOMARKAPD study. Alzheimers Dement. 2019; https://doi.org/10.1016/j.jalz.2019.01.015.

32. Wildsmith KR, Schauer SP, Smith AM, Arnott D, Zhu Y, Haznedar J, et al. Identification of longitudinally dynamic biomarkers in Alzheimer's disease cerebrospinal fluid by targeted proteomics. Mol Neurodegener. 2014;9:22 https://doi.org/10.1186/1750-1326-9-22.

33. van Rossum IA, Vos SJB, Burns $L$, Knol DL, Scheltens $P$, Soininen $H$, et al. Injury markers predict time to dementia in subjects with $\mathrm{MCl}$ and amyloid pathology. Neurology. 2012;79:1809-16 https://doi.org/10.1212/WNL. Ob013e3182704056.

34. Kester Ml, van der Vlies AE, Blankenstein MA, Pijnenburg YAL, van Elk EJ, Scheltens $P$, et al. CSF biomarkers predict rate of cognitive decline in Alzheimer disease. Neurology. 2009;73:1353-8 https://doi.org/10.1212/WNL. OB013E3181BD8271.

35. Jansen WJ, Ossenkoppele R, Knol DL, Tijms BM, Scheltens P, Verhey FRJ, et al. Prevalence of cerebral amyloid pathology in persons without dementia. JAMA. 2015;313:1924 https://doi.org/10.1001/jama.2015.4668.

36. Slot RER, Kester MI, Van Harten AC, Jongbloed W, Bouwman FH, Teunissen $C E$, et al. ApoE and clusterin CSF levels influence associations between APOE genotype and changes in CSF tau, but not CSF A 42 , levels in nondemented elderly. Neurobiol Aging. 2019;79:101-9.

37. Konijnenberg E, Tijms BM, Gobom J, Dobricic V, Bos I, Vos S, et al. APOE $\in 4$ genotype-dependent cerebrospinal fluid proteomic signatures in Alzheimer's disease. Alzheimers Res Ther. 2020;12:65 https://doi.org/10.1186/ s13195-020-00628-Z.

38. Reus LM, Stringer S, Posthuma D, Teunissen CE, Scheltens P, Pijnenburg $Y A L$, et al. Degree of genetic liability for Alzheimer's disease associated with specific proteomic profiles in cerebrospinal fluid. Neurobiol Aging. 2020;93: 144 e1-144.e15.

\section{Publisher's Note}

Springer Nature remains neutral with regard to jurisdictional claims in published maps and institutional affiliations. 